\title{
166
}

\section{Deutsch-amerikanische Koordinierungsbesprechungen}

III A 4-81.00/430/63 geheim

13./15. Mai $1963^{1}$

Betr.: Deutsch-amerikanische Koordinierungsbesprechungen am 13. und 15. Mai 1963 in Bonn

Anlg.: $-1-^{2}$

Unter dem Vorsitz von MD Dr. Sachs fanden am 13. und 15. Mai 1963 im Auswärtigen Amt Koordinierungsbesprechungen mit einer amerikanischen Gruppe über militärische Ausrüstungshilfe und Waffenlieferungen an Entwicklungsländer statt. Die amerikanische Delegation setzte sich aus Vertretern des State Department, der Department of Defense, der AID ${ }^{3}$ und der Botschaft zusammen; amerikanischer Delegationsleiter: Deputy Assistant Secretary of State, Kitchen. (Einzelheiten s. Teilnehmerliste). ${ }^{4}$

Die Besprechung der einzelnen Tagesordnungspunkte, die zum Teil in veränderter Reihenfolge behandelt wurden, ergab folgendes:

\section{Allgemeine Gesichtspunkte}

Man einigte sich eingangs, die Besprechungen als "geheim“ zu klassifizieren. Der Presse soll auf Anfrage mitgeteilt werden, daß aus Washington eine Gruppe zu Besprechungen über allgemeine Fragen der Entwicklungshilfe nach Bonn gekommen sei. Ein Kommuniqué ist nicht vorgesehen. Von amerikanischer Seite werden unter Hinweis auf deutsch-amerikanische Vorbesprechungen im Februar d. J. ${ }^{5}$ informelle Vereinbarungen über eine Konsultation vor der Übernahme neuer Verpflichtungen durch beide Länder auf dem Gebiet der militärischen Hilfe gewünscht. Hierbei müsse im einzelnen geprüft werden, welches Geberland in einem bestimmten Gebiet bevorzugt in Aktion treten soll.

Eine gegenseitige Unterrichtung über allgemeine und spezielle Fragen der Militärhilfe sei erwünscht.

Ziel der amerikanischen Militärhilfe sei die Sicherung der freien Welt. Die deutsche Hilfe sollte dabei in denjenigen Ländern erhöht werden, die wie die Türkei, der Iran und Afghanistan den Deutschen durch traditionell gute Be-

1 Durchdruck für Ministerialdirektor Jansen.

Die Gesprächsaufzeichnung wurde von Hilfsreferent Stübel am 16. Mai 1963 gefertigt.

2 Teilnehmerliste zur Gesprächsaufzeichnung.

3 Die „Agency for International Development“ war die federführende amerikanische Behörde für Fragen der Entwicklungspolitik.

4 Neben Ministerialdirektor Sachs nahmen auf deutscher Seite 14 weitere Personen, auf amerikanischer Seite neben Unterstaatssekretär Kitchen 9 weitere Personen an der Besprechung teil.

5 Die Vorbesprechungen für das Treffen fanden im Rahmen eines Besuchs des Staatssekretärs im amerikanischen Verteidigungsministerium, Gilpatric, am 13. Februar 1963 in Bonn statt. Vgl dazu die Aufzeichnung des Leiters des Referats „Internationale Wirtschaftsfragen der Verteidigung“, von Stechow, vom 15. Februar 1963; Abteilung III (III A 4), VS-Bd. 174.

Zum Besuch vgl. bereits Dok. 92. 
ziehungen verbunden seien, oder wo die Bundesrepublik sonst geeignet erscheine, dem Westen eine neue Stimme zu gewinnen (Beispiel Guinea ${ }^{6}$ ).

Im übrigen beliefen sich die einzelnen, kleineren Hilfevorhaben der USA, vor allem in Schwarz-Afrika, nur auf 2,5\% der gesamten Militärhilfe, die überwiegend in 8 Ländern, insbesondere in Schwerpunktgebieten (z. B. Korea), eingesetzt werde. Grundsätze der US-Militärhilfe seien: Stärkung des politischen Vertrauens in den Westen und der inneren Sicherheit, die oft weit bedrohter sei als die äußere (z. B. Griechenland), Förderung der wirtschaftlichen Entwicklung durch „dual purpose“-Vorhaben ${ }^{7}$, etwa im Rahmen des Civic ActionProgrammes 8 .

Deutscherseits weist Ministerialdirektor Dr. Sachs darauf hin, daß die Tatsache einer militärischen Ausrüstungshilfe der Allgemeinheit in der Bundesrepublik nicht bekannt sei ${ }^{9}$; diese habe dagegen die Notwendigkeit einer Entwicklungshilfe bereitwillig anerkannt. Problematisch sei die Verteidigungshilfe an Staaten in Asien und Afrika, die zu politischer Verstimmung der Nachbarstaaten führe. Weiter müsse von der westlichen Welt auch der unter Ostblockeinfluß erhobene Vorwurf des Neokolonialismus berücksichtigt werden.

Ministerialdirigent Böker weist auf die unterschiedlichen Motive (fiskalische, wirtschaftliche usw.) für eine Militärhilfe hin, die alle nicht ausschlaggebend für die Initiative auf diesem Gebiet sein dürften. Die Bundesrepublik wolle ihr politisches Ansehen nicht durch einen Übereifer auf dem Gebiet der Verteidigungshilfe strapazieren oder durch solche Hilfe indirekt in örtliche Konflikte eingreifen. Sie sei vielmehr bestrebt, sich mit den NATO-Partnern, soweit diese z. B. durch ehemalige koloniale Beziehungen besonders interessiert seien, abzustimmen.

Von deutscher wie von amerikanischer Seite wurde es abgelehnt, dritten Staaten eine Verteidigungshilfe aufzudrängen oder ihnen dadurch unverhältnismäßige Belastungen aufzuerlegen. Von amerikanischer Seite wird in diesem Zusammenhang auf die oft unrealistischen Anfragen hingewiesen. Ministerialdirektor Dr. Sachs betont, eine allgemeine Planung sei schwierig; jeder Fall müsse individuell, auch unter dem Gesichtspunkt einer Konkurrenz des Ostblocks beurteilt werden.

Von amerikanischer Seite wurde sodann eingehend die Organisation der Militärhilfe dargelegt, die im Rahmen eines 5-Jahresplans jährlich in den Einzelheiten festgelegt wird unter Zusammenwirken verschiedener Regierungsorganisationen in Washington und in den betreffenden Ländern.

6 Nachdem im März/April 1960 eine Anerkennung der DDR durch Guinea befürchtet worden war, gelang es der Bundesrepublik in der Folgezeit, das Land durch stabilisierende Maßnahmen, wie ein Handelsabkommen und auch Ausrüstungshilfen, auf einem pro-westlichen Kurs zu halten. Zur Ausrüstungshilfe für Guinea vgl. bereits Dok. 150, besonders Anm. 10.

7 Vgl. dazu Dok. 150, Anm. 8.

8 Im Rahmen dieses Programms unterstützte die amerikanische Regierung Einsätze lokaler Militäreinheiten zugunsten „ziviler Aktionen“. Präsident Kennedy erklärte am 13. März 1962 dazu: „In addition to placing emphasis on the improvement of internal security forces, we are giving increased attention to the contribution which local military forces can make through civic action programs to economic and social development." Vgl. Public PaPers, Kennedy 1962, S. 215.

9 Vgl. dazu auch Dok. 193. 
Die Durchführung liegt danach weitgehend bei den Militärbehörden bzw. in den Empfängerländern bei den MAAG (Military Assistance Advisory Groups). Wichtig für die Beurteilung von Hilfsvorhaben sei die Kapazität der Empfängerländer, mit dem gelieferten Rüstungsmaterial zu arbeiten, z. B. Treibstoff für die Fahrzeuge und technisch ausgebildetes Personal für die Bedienung und Wartung der Waffen und Anlagen bereitzustellen. Man könne davon ausgehen, daß in den neuen afrikanischen Staaten insgesamt nicht mehr als 100 200 Hochschulabsolventen für den zivilen und den Militärbedarf des Landes verfügbar seien. Die Hilfe müsse nach Prioritäten abgestimmt werden, wobei oft im Empfängerland bei den zivilen Verwaltungsstellen und dem Militär gegensätzliche Ansichten über den Vorrang bestünden.

Für die Vereinigten Staaten spielten auch politische Gesichtspunkte eine besondere Rolle; das Einhandeln von Stützpunkten sei ein spezifisch amerikanisches Problem. Bestimmte Vorhaben seien an die ausdrückliche Genehmigung des Präsidenten gebunden (z. B. Begrenzung der Verteidigungshilfe für lateinamerikanische Staaten).

\section{Irak}

Gestreift wurde in diesem Zusammenhang die Frage einer westlichen Verteidigungshilfe für den Irak, dessen politische Struktur für eine solche Initiative des Westens noch nie so günstig gewesen sei wie nach der Beseitigung des Kassem-Regimes. ${ }^{10}$ Von den Vereinigten Staaten würden 40-50 Tank-Transporter geliefert, um zunächst einmal mit dem irakischen Militär ins Gespräch zu kommen und die einseitige Abhängigkeit des Landes vom Ostblock zu lockern.

Vor einer Darstellung der deutschen Organisation der Ausrüstungshilfe erwähnt Ministerialdirektor Dr. Sachs verschiedene besondere Fragen in diesem Zusammenhang:

1) die Lieferung von Surplus-Material im Rahmen der amerikanischen Verteidigungshilfe;

2) die Begründung einer Partnerschaft durch einen eigenen, in den Richtlinien festgelegten Beitrag der Empfängerländer zur Verteidigungshilfe;

3) die Schwierigkeiten, die sich aus dem Zeitablauf zwischen der Zusage einer Hilfe und ihrer praktischen Durchführung, u. a. infolge von längeren Lieferfristen ergeben.

Frage 1) wird dahingehend beantwortet, daß Lieferungen von Überschuß-Material noch nicht einmal $10 \%$ der amerikanischen Militärhilfe erreichten und man sich bemühe, diesen Anteil möglichst gering zu halten. Wie bei den eigenen Truppen werde auch bei den Empfängerländern die Zuteilung von neuem Material von der Dringlichkeit abhängig gemacht.

\section{Deutsche Organisation}

Vortragender Legationsrat I. Klasse von Stechow schildert das Verfahren, das sich bisher in der Bundesrepublik für die Verteidigungshilfe herausgebildet hat und das im allgemeinen auf Initiative des betreffenden Landes entweder

10 Am 8. Februar 1963 wurde die Regierung des Ministerpräsidenten Kassem, der am folgenden Tag standrechtlich erschossen wurde, gestürzt und durch eine sogenannte Revolutionsregierung ersetzt. Vgl. Europa-ARCHIV 1963, Z $49 \mathrm{f}$. 
über dessen Botschaft in Bonn oder über den deutschen Militärattaché aufgenommen wird. Die Beurteilung der politischen Gesichtspunkte erfolgt in enger Zusammenarbeit mit unserer jeweiligen Botschaft durch die politischen Abteilungen des Auswärtigen Amtes. Legationsrat I. Klasse Schwartze (Ref. II 7) weist darauf hin, daß die deutschen Maßnahmen nicht als Militärhilfe, sondern als Ausrüstungshilfe (Equipment Aid) bezeichnet werden. Ministerialdirektor Dr. Sachs teilt mit, daß im Gegensatz zu den Vereinigten Staaten der Bundestag mit Fragen der Ausrüstungshilfe nicht befaßt werde, da dieser Komplex geheim sei und aus einem Fonds finanziert wird, der nach einer Entscheidung des Bundesverteidigungsrates ${ }^{11}$, dessen Aufbau kurz erklärt wurde, vom Bundesverteidigungsministerium verwaltet wird. Insgesamt dürften bisher nur wenige Mio. DM verausgabt worden sein.

Die amerikanische Frage nach der Bearbeitung von dringlichen Notfällen (Emergencies) wird dahingehend beantwortet, daß in solchen Fällen ein Kabinettsbeschluß herbeigeführt werde und gegebenenfalls das Bundesfinanzministerium die erforderlichen Mittel irgendwie bereitstelle.

\section{Militärhilfe an Indien und Pakistan}

Zu der Frage deutscher Flugzeuglieferungen an Pakistan ${ }^{12}$ wird von amerikanischer Seite mitgeteilt, die pakistanische Luftwaffe besitze an sich bereits soviele Flugzeuge, wie sie praktisch verwenden könne, da die technischen Gegebenheiten (zu wenig Piloten, mangelhafte Organisation und Ausbildung) enge Grenzen setzten; offenbar sei der Wunsch nach weiteren Flugzeugen vor allem eine Prestigefrage. Das in Aussicht genommene Flugzeug F-86 K sei zu 80\% mit der ungleich einfacheren von den USA gelieferten F-86 F identisch; die Unterschiede lägen im Bewaffnungssystem und den Einrichtungen für die Verbindung mit den Bodenstationen (Allwetterjäger); das letztere falle aber für Pakistan, wo diese Bodeneinrichtungen weitgehend fehlten, nicht als Vorteil ins Gewicht. Die USA hätten jedoch gegen den geplanten Verkauf keine politischen Bedenken, und Minister Rusk habe das den Pakistanern in Karachi mitgeteilt. ${ }^{13}$

Ministerialdirektor Dr. Sachs schildert die deutsche Indien-Hilfe und die Sonderkredite, die Indien für Lastkraftwagen, Stahlplatten usw. gewünscht, aber - da dies vom Kabinett abgelehnt wurde - nicht erhalten habe. ${ }^{14}$ An den Dü-

11 Der Beschluß des Bundesverteidigungsrats vom 15. Juni 1961 ermächtigte das Bundesministerium der Verteidigung, „im Einvernehmen mit dem Auswärtigen Amt über Einzelfälle von Ausrü stungshilfe selbständig zu entscheiden. Das Auswärtige Amt prüft die politischen Belange, sorgt für die Koordinierung mit den Maßnahmen der allgemeinen Entwicklungshilfe sowie für die Unterrichtung oder Beteiligung anderer Ressorts. Falls eine Einigung der Ressorts nicht erzielt wird, entscheidet der Bundesverteidigungsrat." Vgl. die Aufzeichnung des Ministerialdirektors Allardt vom 8. Oktober 1962; Abteilung III (III A 4), VS-Bd. 174; B 150, Aktenkopien 1962. Zur Unterrichtung eines kleinen Kreises von Bundestagsabgeordneten über die Ausrüstungshilfe vgl. Dok. 193, Anm. 1.

12 Vgl. dazu Abteilung III (III A 4), VS-Bd. 211.

13 Der amerikanische Außenminister Rusk hielt sich vom 30. April bis 1. Mai 1963 anläßlich der Ministerratstagung der CENTO in Karachi auf. Vgl. dazu EurOPA-ARCHIV 1963, Z 123 f.; AdG 1963, S. 10554

14 Zur Ausrüstungshilfe für Indien vgl. auch Dok. 150, Anm. 16. 
senflugzeugen, über die mit dem indischen Militärattaché15 verhandelt wurde $^{16}$, sei die indische Seite offenbar nicht interessiert und habe bisher nicht reagiert. Um eine Verstimmung der Inder zu vermeiden, rege die Bundesrepublik an, die deutschen Flugzeuge im Rahmen eines Dreiecksgeschäfts über die Vereinigten Staaten zu liefern, die durch ihre umfangreiche Militärhilfe an Indien auch Pakistan gegenüber freiere Hand hätten.

Amerikanischerseits wurde eine Prüfung dieser Frage zugesagt.

\section{Afrika}

Grundsätzlich wurde von amerikanischer Seite zur Militärhilfe für afrikanische Staaten ausgeführt, daß diese Staaten das Gefühl der freien Wahl haben müßten und sich hinsichtlich der Militärhilfe nicht auf einen bestimmten Staat angewiesen fühlen sollten. In den ehemals französischen oder britischen Interessengebieten sollen Frankreich oder Großbritannien die Vorhand haben; die deutsche Ausrüstungshilfe für Guinea, Somalia und im Sudan werde begrüßt.

\section{Somalia}

Die amerikanische Expertengruppe, die sich im Anschluß an Besprechungen in London, Bonn ${ }^{17}$ und Rom im April drei Wochen lang in Mogadischu aufhielt und Militäreinrichtungen inspizierte, konnte ihren Bericht noch nicht fertigstellen. Die USA wollten nicht über Lieferungen zur Aufrechterhaltung der inneren Sicherheit und der Grenzkontrolle hinausgehen. Vortragender Legationsrat I. Klasse Steltzer schildert die deutschen Bedenken wegen Äthiopien; man sei deutscherseits daran interessiert, den Eindruck, es handele sich um eine bilaterale deutsche Ausrüstungshilfe für Somalia, zu vermeiden. Die Amerikaner müßten erst den Bericht ihrer Gruppe abwarten. Die Italiener hätten Waffen und Munition versprochen; die Engländer wollten auf dem laufenden gehalten werden im Hinblick auf eine spätere Besserung ihrer Beziehungen zu Somalia. Botschafter Kopf weist warnend darauf hin, daß Somalia sich vom Westen vernachlässigt fühle. Es handele sich nicht um die Aufrechterhaltung eines Gleichgewichts, sondern um die Beseitigung eines Vakuums durch deutsche Hilfe; die USA sollten schwere Ausrüstungen und Waffen liefern; deutscherseits solle man Fahrzeuge und leichtes Material bevorzugen (keine Panzerabwehr). Ministerialdirektor Dr. Sachs regt an, daß die Amerikaner die äthiopische Regierung von der dreiseitig abgestimmten Hilfe für Somalia zu gegebener Zeit unterrichten sollten. ${ }^{18}$

\section{Guinea}

Von amerikanischer und deutscher Seite wird der politische Weg Guineas geschildert, der zur Zeit eine von den Amerikanern begrüßte Wiederannäherung an Frankreich ${ }^{19}$ erkennen läßt; es werden Beispiele für das hohe Ansehen

15 A. P. Sharma.

16 Vgl. dazu Abteilung III (III A 4), VS-Bd. 211.

17 Vgl. dazu Abteilung III (III A 4), VS-Bd. 174.

18 Zur Ausrüstungshilfe für Somalia vgl. bereits Dok. 150, Anm. 7.

19 Im Zusammenhang mit der Proklamation der Unabhängigkeit Guineas 1958 kam es zu Spannungen mit Frankreich. Im Herbst 1962 wurden Verhandlungen zwischen beiden Staaten aufgenom- 
Sekou Tourés bei den führenden Persönlichkeiten der neuen afrikanischen Staaten zitiert. Vortragender Legationsrat I. Klasse von Stechow berichtet über das deutsch-guineische Verwaltungsabkommen vom Herbst $1962^{20}$ und über Einzelheiten der bisherigen Durchführung. Der vergleichsweise hohe Betrag von 10 Mio. DM hängt, wie Ministerialdirektor Dr. Sachs betont, mit der Lieferung kostspieliger Maschinen zusammen; es handele sich um echte „dual purpose“-Hilfe. Die Regierung Guineas habe weitere Wünsche angemeldet, die mit einem Wert von ca. 20 Mio. DM in keinem rechten Verhältnis zur bisherigen zivilen Entwicklungshilfe stehen dürften. Es sei noch offen, ob diesen Wünschen zu einem Teil oder vielleicht im Laufe der Zeit sogar in vollem Umfang entsprochen werden würde. Dabei müßten auch etwaige Beiträge Frankreichs oder anderer Staaten zur Ausrüstung Guineas in Rechnung gestellt werden.

Von amerikanischer Seite wurde erklärt, die Vereinigten Staaten hielten sich in diesem Gebiet zurück, verfolgten aber mit Interesse, was in Guinea seitens der Bundesrepublik und von anderer Seite unternommen wird.

\section{Nigeria}

Die politischen Interessen der Vereinigten Staaten an Nigeria zielen darauf $a b$, einen Rüstungswettlauf zu verhindern und die bisherige Ausrüstungshilfe anderer Staaten eher zu ergänzen als an ihre Stelle zu treten; weiter sei die Militärhilfe auf die Aufrechterhaltung der inneren Sicherheit ausgerichtet; sie solle auf ein Mindestmaß begrenzt werden. Es komme darauf an, einem Vordringen des Ostblocks zu begegnen und die Entwicklung des westlich ausgerichteten anti-kommunistischen Militärs zu fördern. Einstweilen geben die USA lediglich eine Ausbildungshilfe, die für 1963 und 1964 mit $300000 \$$ jähr lich angesetzt ist.

Die deutsche Ausrüstungshilfe, die sich auf Unterstützung beim Aufbau einer nigerianischen Luftwaffe beschränkt, wird von Vortragendem Legationsrat I. Klasse von Stechow im einzelnen geschildert; es handele sich vornehmlich um Ausbildungshilfe; die erforderlichen Flugzeuge kaufe Nigeria in der Bundesrepublik. ${ }^{21}$ Für gebrauchte Flugzeuge betrage der Preis etwa $30 \%$ des Neuwertes. Der Ausbildung des Luftwaffenpersonals entsprechend werde die Lieferung der Flugzeuge nur langsam anlaufen.

Eine amerikanische Frage nach der Qualität der nigerianischen Armee beantwortet Vortragender Legationsrat I. Klasse Steltzer dahingehend, daß die Engländer ein besseres Erbe hinterlassen hätten als die Franzosen in ehemaligen Kolonialgebieten; auch sei der Anteil der Inländer unter den höheren Offizieren größer als im französischen Einflußbereich. Man habe geglaubt, das Risiko einer gewissen Verstimmung Ghanas auf sich nehmen zu müssen. Die amerikanische Besorgnis, daß die Nigerianer sich mit dem LuftwaffenVorhaben übernehmen könnten, wird deutscherseits nicht geteilt.

\footnotetext{
Fortsetzung Fußnote von Seile 532

men, um die offenen Fragen zu klären. Am 23. Mai 1963 wurden entsprechende vertragliche Regelungen getroffen. Vgl. dazu AdG 1963, S. 10594 f.

$20 \mathrm{Vgl}$. Abteilung III (III A 4), VS-Bd. 173.

$21 \mathrm{Vgl}$. dazu bereits Dok. 150, Anm. 13.
} 


\section{Sudan}

Unsere zur Zeit laufenden Vorhaben sind den USA bereits bekannt. Die Verteidigungshilfe der Vereinigten Staaten beschränkt sich auf Ausbildungsvorhaben (1963 weniger als $82000 \$ ; 1964 \mathrm{rd}$. $50000 \$$ ). Auf die amerikanische Frage nach der innerpolitischen Stabilität des Sudan antwortet Legationsrat Schlagintweit, daß man deutscherseits keine umwälzenden Veränderungen im Sudan erwarte; etwaige Änderungen im Kabinett dürften mehr persönlicher als sachlicher Art sein. Der Sudan sei das einzige größere arabische Land, dem die Bundesrepublik Ausrüstungshilfe gewähre; sie glaube nicht, daß Israel, das dem Sudan nicht benachbart sei, wegen dieser Hilfe Vorstellungen erheben werde. Im Rahmen der Vereinbarungen seien bereits einige Lieferungen erfolgt. ${ }^{22}$

\section{Tanganjika}

Deutscherseits wird die Vorgeschichte der Schenkung von zwei armierten Küstenschutzbooten anläßlich der Ausrufung der Republik Tanganjika ${ }^{23}$ geschildert; die Regierung in Daressalam beabsichtige, weitere Küstenschutzboote zu kaufen und wünsche außerdem einen deutschen Militärberater. Über die Entsendung des letzteren laufe eine Konsultation mit den Briten. ${ }^{24}$ Die amerikanische Delegation wirft die Frage politischer Veränderungen durch den eventuellen Zusammenschluß von Tanganjika mit Kenia und Uganda zu einer Föderation $^{25}$ auf. Vortragender Legationsrat I. Klasse Steltzer weist darauf hin, daß die drei Staaten von früher her noch gewisse Verbindungen durch Währungseinheit und gemeinsamen Postdienst besäßen. Zur politischen Lage Tanganjikas führt er weiter aus, daß der neue Verteidigungsminister Kambona als linksgerichtet und nicht sehr zuverlässig gelte. Er sei eher gegen England eingestellt und bevorzuge aus diesem Grunde die Bundesrepublik. Vielleicht liege hier eine Chance, den Einfluß des Westens in Tanganjika zu stärken.

Von amerikanischer Seite wird die Möglichkeit eines Verteidigungsabkommens angedeutet. Der deutsche Einfluß in diesem Gebiet wird begrüßt.

\section{Madagaskar}

Deutscherseits wird die Entwicklung der deutschen Ausrüstungshilfe für Madagaskar (fünf Küstenschutzboote) und ihre Abstimmung mit Frankreich dargestellt. $^{26}$ Die amerikanische Seite gibt ihrer Verwunderung über die große Zahl französischer Truppen (40000 Mann) Ausdruck, die Frankreich auf der Insel stationiert hat, während die einheimischen Streitkräfte nur ca. $\mathbf{5 0 0 0}$ Mann betragen.

\footnotetext{
22 Vgl. dazu bereits Dok. 119, besonders Anm. 5.

23 Tanganjika wurde am 9. Dezember 1961 unabhängig. Vgl. Europa-Archiv 1962, Z 7.

24 Vgl. dazu Abteilung III (III A 4), VS-Bd. 193.

25 Zu dem Plan, bis Ende 1963 eine Ostafrikanische Föderation aus den Staaten Uganda, Kenia und Tanganjika zu schaffen, vgl. Dok. 171, Anm. 5.

26 Vgl. dazu Abteilung III (III A 4), VS-Bd. 172.
} 


\section{Mali}

Besonderes Interesse bekundet die amerikanische Seite an Mali. Sie wird darüber informiert, daß Mali keinerlei Militärhilfe von der Bundesrepublik erhält; dies überlasse man den Franzosen. Von deutscher Seite seien lediglich im Rahmen ziviler Vorhaben 300-400 schwere Lastkraftwagen geliefert worden.

Die amerikanische Hilfe ist für 1963 mit 1,2 Mio. \$ und für 1964 mit 700000 \$ angesetzt. Vorgesehen ist die Lieferung eines Laboratoriums britischer Herkunft, die Ausbildung von Luftwaffenpiloten bei eventueller Lieferung von zwei bis drei C-47 Flugzeugen im Haushaltsjahr 1965, Sachlieferungen und Ausbildungshilfe für Pioniereinheiten sowie die Ausbildung auf dem Nachrichten- und Transportsektor bei beschränkten Sachlieferungen. Die Vereinigten Staaten hätten sich mit dieser Militärhilfe nur eingeschaltet, um nach dem Rückzug der Franzosen aus diesem Gebiet dem tschechoslowakischen Einflu $\beta^{27}$ entgegenzuwirken; die SBZ zeige sich im Gegensatz zu früher an Mali jetzt nicht mehr interessiert. ${ }^{28}$ Gegen eine etwaige deutsche Ausrüstungshilfe in Mali würde amerikanischerseits nichts einzuwenden sein, umsoweniger als die Vereinigten Staaten sich dort nicht stärker engagieren wollten.

\section{Ende des ersten Sitzungstages}

Die Sitzung am 15. Mai vormittags beginnt deutscherseits unter dem Vorsitz von Ministerialdirektor Dr. Knieper (Bundesministerium der Verteidigung).

\section{Kommerzielle Waffengeschäfte}

In grundsätzlichen Ausführungen erklärt die amerikanische Seite, „grant aid" (geschenkweise Hilfe) gewährten die USA denjenigen Ländern, deren Verteidigungskraft erhöht werden sollte, denen aber die Mittel dafür fehlten. Ausschlaggebend für die Berechnung der Hilfe sei die Zahlungsfähigkeit des Empfängerlandes; die Rücksicht auf die amerikanische Zahlungsbilanz stelle nur einen Gesichtspunkt unter anderen dar. Für das Haushaltsjahr 1962/63 betrügen die Waffenverkäufe 1,055 Mrd. \$ und die „grant aid“ 1,60 Mrd. \$. Die Kreditfristen bei Waffenverkäufen beliefen sich auf 3 , ausnahmsweise auf 6-7 Jahre; die Zinsen rangierten zwischen 0 und 5\%.

Nach einem Hinweis auf den Austausch persönlicher Kontakte im Rahmen der amerikanischen Verteidigungshilfe für Birma wird die amerikanische Auffassung über eine Unterstützung Indonesiens dahingehend geschildert, daß man in den indonesischen Landstreitkräften einen stabilisierenden Faktor sehe. Das Heer stelle nicht nur eine Kampftruppe dar, sondern erfülle auch soziale und politische Aufgaben. Es stehe den amerikanischen Vorhaben der „civic action“ aufgeschlossen gegenüber. Die Armee sei antikommunistisch, so daß sich die Bemühungen des Ostblocks auf Marine und Luftwaffe konzen-

27 Höhepunkt der tschechoslowakisch-malischen Kontakte war der sechstätige Besuch des Staatspräsidenten Keita in der ČSSR im Juni 1962. Vgl. dazu Europa-ARCHIV 1962, Z 137.

28 Noch im April 1963 hielt sich der Stellvertretende Außenminister der DDR, Winzer, zur Erörterung von Fragen der wirtschaftlichen und kulturellen Zusammenarbeit in Mali auf. Vgl. EuropAARchiv 1963, Z 108. 
trierten. Die Vereinigten Staaten würden es begrüßen, wenn sich die Bundesrepublik mit entsprechenden Maßnahmen in Indonesien engagiere.

Ministerialdirektor Dr. Knieper (Bundesministerium der Verteidigung) führt aus, daß die Bundesrepublik im Gegensatz zur amerikanischen ,grant aid“ grundsätzlich auf einem eigenen finanziellen Beitrag des Empfängerlandes (Sudan nahezu ein Drittel, Somalia 15\%) bestehe; dies trage dazu bei, die Wünsche auf ein realistisches $\mathrm{Maß}$ zu reduzieren und könne zu einer verantwortungsvolleren Einstellung gegenüber den deutschen Materiallieferungen beitragen.

Ministerialdirigent Böker legt die gesetzlichen Grundlagen der kommerziellen Waffengeschäfte und des deutschen Genehmigungsverfahrens dar. ${ }^{29}$ Das Auswärtige Amt und das Bundesministerium der Verteidigung würden zu allen Anträgen gehört. Im allgemeinen konsultierten die Firmen die zuständigen Behörden vor dem Eintritt in kommerzielle Verhandlungen. Für die ganze deutsche Ausrüstungshilfe sei im übrigen der Mangel an geeignetem Personal, insbesondere bei der Durchführung humanitärer Aufgaben auf diesem Gebiet wie beispielsweise dem Sanitätswesen und der Ausbildung zu bedauern.

Ministerialdirektor Dr. Knieper (Bundesministerium der Verteidigung) spricht sich für eine Fortsetzung des deutsch-amerikanischen Erfahrungsaustausches aus. Immer wieder träten westlich eingestellte Militärpersonen aus Entwicklungsländern an die Bundesrepublik heran; viele dieser Fälle würde man gerne mit der amerikanischen Seite besprechen.

Vergabe von überschüssigem deutschen Rüstungsmaterial

Die amerikanische Seite weist auf den Unterschied zwischen „veraltet“ und „überschüssig“ hin; die überschüssigen Rüstungsgüter könnten beispielsweise bei einzelnen NATO-Verbündeten (Griechenland, Türkei) noch nutzbringend eingesetzt werden. Ministerialdirektor Dr. Knieper (Bundesministerium der Verteidigung) deutet an, daß die Aufrüstungsplanung von $1954^{30} \mathrm{zu}$ den heute vorhandenen großen Überschüssen geführt habe, die schwierig abzusetzen seien. Den Amerikanern seien über den hiesigen Chef der amerikanischen Militärberatergruppe Rüstungsbestände und Bedarf bekannt.

\section{Kongo}

Die Amerikaner teilten mit, sie hätten kein bestimmtes Programm; es seien $3780000 \$$ Militärhilfe für die Ausbildung der kongolesischen Armee nach dem Abzug der UNO-Streitkräfte ${ }^{31}$ vorgesehen.

29 Die Exportkontrolle für Waffen beruhte im wesentlichen auf dem Kriegswaffenkontrollgesetz vom 20. April 1961 und dem Außenwirtschaftsgesetz vom 28. April 1961. Vgl. dazu Dok. 124, Anm. 8, und Dok. 133, Anm: 11.

30 Nach dem Scheitern der Europäischen Verteidigungsgemeinschaft im August 1954 wurden die Planungsarbeiten für den Aufbau von Streitkräften der Bundesrepublik Deutschland neu aufgenommen. Im Frühjahr 1955 fanden die Überlegungen einen ersten Abschluß.

31 Korrigiert aus NATO-Streitkräfte.

In dem am 30. Juni 1960 von Belgien unabhängig gewordenen Kongo (Léopoldville) brach nach dem Abfall der Provinz Katanga ein Bürgerkrieg aus, der erst im Januar 1963 aufgrund des Einsatzes von UNO-Truppen beendet werden konnte.

Die letzten UNO-Truppen verließen im Juni 1964 das Land. Vgl. EuropA-ARCHIV 1964, Z 151. 


\section{Afghanistan}

Einen erneuten amerikanischen Hinweis auf den guten Ruf der Deutschen in Afghanistan beantwortet Ministerialdirigent Böker mit der Bemerkung, man müsse die Nachbarschaft mit der Sowjetunion und Pakistan berücksichtigen, der Afghanistan Rechnung tragen müsse. Die Sowjetpropaganda dort richte sich genau so gegen die Bundesrepublik wie gegen die USA.

\section{Iran}

Der Iran wirft als Mitglied des CENTO-Paktes ${ }^{32}$ keine besonderen Probleme auf.

\section{Türkei und Griechenland}

Bei Griechenland soll sich, wie Ministerialdirektor Dr. Knieper darlegt, der deutsche Materialbeitrag im Rahmen der NATO-Verteidigungshilfe auf Lieferungen beschränken, die von direktem Nutzen für die griechischen Streitkräfte sind. Die Durchführung der Vereinbarungen sei zeitraubend, so daß der deutsche Beitrag wohl nicht innerhalb des Jahres 1963 voll in Anspruch genommen werden könne. ${ }^{33}$

Bei der Türkei ständen gleichfalls die Landstreitkräfte im Vordergrund der Erwägungen, während sich der kürzlich verstorbene türkische Marineattaché $^{34}$ in Bonn unter dem Einfluß eines gewissen Gegensatzes zwischen Armee und Marine um die Lieferung kleiner deutscher U-Boote bemüht habe ${ }^{35}$ Doch seien bisher weder auf kommerziellem Wege noch regierungsseitig Vereinbarungen über deutsche U-Bootlieferungen an die Türkei getroffen worden.

\section{VAR und Nahost}

Die amerikanische Seite stellt fest, daß die Beziehungen zu Syrien nicht mehr so eng wie früher seien. Die Mittel der Vereinigten Staaten reichten nicht aus, um das ganze Gebiet der VAR zu kontrollieren. In Jordanien wünsche Nasser in der nächsten Zeit keine Unruhe; die für Nasser eingestellten Elemente in Jordanien handelten auf eigene Faust. Für 1963 sei die amerikanische Militärhilfe mit rd. 5,6 Mio. \$ und für 1964 mit rd. 3,7 Mio. \$ angesetzt. Das Programm schließe nicht nur Panzer, Geschütze und Ausbildungsvorhaben, sondern auch ein Wasserversorgungsprojekt und Hospitaleinheiten ein.

Über die deutsche Einstellung gegenüber dem Nahen Osten bemerkt Ministerialdirigent Böker, daß die Bundesrepublik an ihrer Zurückhaltung in diesem Gebiet auch in Zukunft festhalten werde. Von den Schwierigkeiten mit den in Ägypten privat tätigen Fachleuten ausgehend ${ }^{36}$, stellt er fest, daß besonders im Irak, aber auch in Saudi-Arabien, Jordanien und Ägypten die Tätigkeit

32 Dem Verteidigungsbündnis zwischen der Türkei und dem Irak vom 24. Februar 1955 (BagdadPakt) traten bis Ende 1955 Großbritannien, Pakistan und der Iran bei. 1956 kamen die USA als Beobachter hinzu. Nach dem Ausscheiden des Irak erhielt das Bündnis 1959 den Namen CENTO (Central Treaty Organization). Vgl. dazu Europa-Archiv 1955, S. 8003f.; Europa-Archiv 1959 , D 209-211 und D 370-372.

33 Zur Verteidigungshilfe für Griechenland vgl. Abteilung III (III A 4), VS-Bd. 162 und VS-Bd. 176.

34 Muzaffer Elaldi.

35 Vgl. dazu Abteilung III (III A 4), VS-Bd. 162. Dazu auch Dok. 151.

36 Vgl. dazu besonders Dok. 133. 
westlicher Länder begrüßt werde, daß die Bundesrepublik sie aber grundsätzlich den Alliierten überlassen müsse.

Die amerikanische Delegation weist auf gewisse innenpolitische Schwierigkeiten mit der Hilfe an arabische Länder hin; man würde es bereits begrüßen, wenn deutscherseits eine Beteiligung an der sogenannten „civic action“ erfolge. Dem wird entgegengehalten, daß sich im Bundestag für eine solche Hilfe in Nahost keine Mehrheit finden würde. Ministerialdirektor Dr. Sachs erklärt, der ausschlaggebende militärische Faktor in Nahost sei die im Mittelmeer stationierte amerikanische 6. Flotte. Die amerikanische Seite erklärt, dieser Schirm bedürfe der Ergänzung durch Hilfe, und führt Beispiele dafür an, wie mit kleinen Beiträgen bei bestimmten Projekten eine erhebliche Publikumswirkung erzielt werden könne. Die deutsche Seite beharrt auf ihrer durch die Lage gegenüber Israel gebotenen Zurückhaltung in diesem Raum.

Lateinamerika

Zur Frage einer deutschen Militärhilfe für lateinamerikanische Staaten $^{37}$ sagt Ministerialdirektor Dr. Sachs einleitend, die Bundesrepublik halte sich zurück; auch liege die Bedrohung dieser Staaten eher auf wirtschaftlichem, sozialem und politischem Gebiet als auf dem Verteidigungssektor. Militärisch stehe dieses Gebiet wohl unter dem Schirm der Vereinigten Staaten.

Die Ziele der Vereinigten Staaten in Lateinamerika werden amerikanischerseits darin gesehen, dem nationalen Prestige der Länder auf dem Rüstungssektor nicht so weit Rechnung zu tragen, daß das wirtschaftliche Gleichgewicht dadurch gestört werde. Für die einzelnen Staaten werde eine weitgehend gleiche Ausbildung und Ausrüstungshilfe angestrebt, so daß die einzelnen Vorhaben ausgetauscht werden könnten.

Ministerialdirektor Dr. Knieper (Bundesministerium der Verteidigung) schildert die geringe Zahl deutscher Ausbildungsvorhaben für Einzelpersonen.

\section{Portugal und Spanien}

In Abweichung von der Tagesordnung bitten die Amerikaner um eine Darstellung der deutsch-portugiesischen Beziehungen auf dem Verteidigungssektor ${ }^{38}$ Dazu führt Ministerialdirektor Dr. Knieper (Bundesministerium der Verteidigung) im einzelnen aus, der Generalstab befürworte eine Zusammenarbeit auf militärischem Gebiet mit Portugal, da dieses Land außerhalb des ballistischen Zielgebiets der Sowjetunion liege. Infolgedessen seien Lager für die F-104 GFlugzeuge und andere Depots dort errichtet worden ${ }^{39}$; Notlazarette befänden sich in Vorbereitung; auch Ausbildungsmöglichkeiten seien vorgesehen. Die Bundesrepublik habe laufend Munition in Portugal bezogen, doch seien die Mengen rückläufig. Auch die kommerziellen rüstungswirtschaftlichen Beziehungen seien zurückgegangen. Deutsche Rüstungs- und Zivillieferungen seien von Portugal aus nach Angola weitergeliefert worden, was zu erheblichen politischen Schwierigkeiten geführt habe..$^{40}$ Dies erkläre die vorerwähnte rückläu-

37 Vgl. dazu Abteilung III (III A 4), VS-Bd. 168.

38 Vgl. dazu Abteilung III (III A 4), VS-Bd. 164.

$39 \mathrm{Vgl}$. dazu weiter Dok. 374.

40 Vgl. dazu auch Dok. 312. 
fige Entwicklung. Über die militärische Planung im NATO-Bereich seien die USA unterrichtet. Aufgrund der deutschen Depots in Portugal wünsche die portugiesische Regierung nun auch eine Unterstützung bei der Luftverteidigung; dabei sei offenbar an eine Art von Notstandshilfe gedacht. Abschließend wird auf die beiden in Portugal stationierten amerikanischen F-104-Staffeln verwiesen.

Die amerikanische Seite meint, Portugal sei es jetzt weniger um eine Militärhilfe als um politische Unterstützung in Afrika zu tun. Die logistischen Probleme hinsichtlich Portugals und der Azoren berührten nicht die USA allein, sondern beträfen die ganze NATO.

In diesem Zusammenhang bezeichnet Ministerialdirektor Dr. Knieper eine Abstimmung hinsichtlich der US-Stützpunkte in Portugal auch für Hawk, Nike und Zeus ${ }^{41}$ als wünschenswert. Die amerikanische Seite begrüßt diese Anregungen und spricht sich für eine enge Fühlungnahme in der Frage einer „kollektiven Luftverteidigung“ aus.

\section{Fortführung der Koordinierung}

Von amerikanischer Seite wird eine Fortführung der Koordinierungsbesprechung vorgeschlagen. Das nächste Gespräch könne im Oktober d.J. in Washington stattfinden ${ }^{42}$; bis dahin würden die amerikanischen Vorbereitungen für das kommende Jahr abgeschlossen sein. Gedacht sei an eine Koordinierung

1) durch laufende Konsultationen auf politischem und militärischem Gebiet und

2) an Gespräche über die militärischen Ausgaben für die einzelnen Gebiete und die daran geknüpften Bedingungen. Im allgemeinen gäben die USA die amerikanischen Zahlen den Empfängerländern nicht bekannt.

Ministerialdirektor Dr. Sachs begrüßt die amerikanische Anregung und bittet das Bundesministerium der Verteidigung um die Bereitstellung des erforderlichen Zahlenmaterials über unsere Ausrüstungshilfe. Ministerialdirektor $D r$. Knieper (Bundesministerium der Verteidigung) teilt dazu mit, daß im Jahre 196330 Mio. DM für Militärhilfe zur Verfügung ständen; dazu komme noch ein Übertrag aus dem Vorjahr in Höhe von 13 Mio. DM. Ursprünglich habe das Bundesverteidigungsministerium für 1963 mit 75 Mio. DM gerechnet. Die Verteidigungshilfe für Griechenland sei in diesen Zahlen nicht enthalten.

Abteilung I (D I/Dg I A), VS-Bd. 123

41 Die raketengestützten Waffensysteme Hawk, Nike und Zeus dienten der Luftabwehr.

42 Zur Besprechung am 5. Oktober 1963 vgl. Dok. 378. 


\section{7}

\section{Gesandter Scholl, Moskau, an Bundesminister Schröder}

Z B 6-1 73/63 streng geheim

Fernschreiben Nr. 391
Aufgabe: 15. Mai 1963, 13.00 Uhr

Ankunft: 15. Mai 1963, 12.53 Uhr

Nur für Minister ${ }^{1}$ und Staatssekretär ${ }^{2}$

Herr Beitz, der hier am 13. Mai eintraf ${ }^{3}$, wurde am 14. vormittags von sowjetischer Seite unterrichtet, daß Chruschtschow ihn für $15.00 \mathrm{Uhr}$ zu sich bitte. Sowjets veröffentlichten am 14. abends Mitteilung, daß Chruschtschow den auf Einladung Außenhandelsministeriums in Moskau weilenden Generalbevollmächtigten der Firma Krupp empfangen und mit ihm ein geschäftliches Gespräch gehabt habe. ${ }^{4}$

Herr Beitz unterrichtete mich soeben. Bei Gespräch mit Chruschtschow waren nur sowjetischer Dolmetscher und ein protokollierender Vertreter Außenhandelsministeriums zugegen. Sowjets hätten auf Wunsch von Beitz, einen seiner Begleiter mit hinzuzuziehen, zum Ausdruck gebracht, daß Chruschtschow ihn gern allein sprechen möchte.

Beitz machte sich während Gesprächs mit Chruschtschow ausführliche Notizen und wird den Herrn Bundesminister nach seiner Rückkehr (Rückflug 22. 5. vorgesehen) eingehend unterrichten. Vorab teilte er mir folgendes mit:

Chruschtschow sei sehr ruhig und konzentriert gewesen. Den größten Teil der Unterhaltung habe er selbst bestritten und zu einer ausführlichen Darstellung der Nachkriegsgeschichte aus seiner Sicht benutzt. Wirtschaftliche Fragen hätten den geringsten Teil des Gesprächs eingenommen. Chruschtschow habe nach Ansicht Beitz' den Eindruck vermitteln wollen, daß er eine kurzfristige Lösung der uns angehenden Fragen nicht erwarte und auch nicht anstrebe. An einer Anheizung des Berlin-Problems ist er nach dem Eindruck von Beitz nicht interessiert. Eine gewaltsame Lösung, so habe er ausdrücklich erklärt, komme nicht in Frage. Er werde auch keine Raketen nach Deutschland schicken lassen, davon könnten auch sowjetische Truppen getroffen werden. Chruschtschow setzte gewisse Erwartungen in den Regierungswechsel; er habe in diesem Zusammenhang Bundesminister Erhard auch namentlich genannt, warte unter Umständen aber auch auf die übernächste Regierung.

Das Wort „Revanchismus“ sei nicht gefallen. Chruschtschow habe auch offen

1 Hat Bundesminister Schröder am 15. Mai 1963 vorgelegen, der handschriftlich verfügte: „Herrn St[aatssekretär] I R[ücksprache]“.

2 Hat Staatssekretär Carstens am 21. Mai 1963 vorgelegen, der nach Rücksprache mit Bundesminister Schröder den Drahtbericht an Staatssekretär Lahr weiterleiten ließ.

3 Der Generalbevollmächtigte der Firma Krupp, Beitz, hielt sich vom 13. bis 22. Mai 1963 in der UdSSR auf. Vgl. dazu auch die Aufzeichnung des Legationsrats I. Klasse Wolff vom 30. Mai 1963; Abteilung II (II 4), VS-Bd. 199; B 150, Aktenkopien 1963.

4 Vgl. Pravda, Nr. 135 vom 15. Mai 1963, S. 1.

Vgl. zu dem Gespräch mit Ministerpräsident Chruschtschow am 14. Mai 1963 auch die von Beitz gefertigte Gesprächsaufzeichnung; Abteilung II (II 5), VS-Bd. 204; B 150, Aktenkopien 1963. 
zum Ausdruck gebracht, daß er mit gewaltsamen Aktionen von unserer Seite nicht rechne.

In der Berlinfrage hat Chruschtschow offenbar die Standardformel (Normalisierung und freie - nicht aber demilitarisierte - Stadt ${ }^{5}$ ) gebraucht. Er habe auch von einem direkten Kulturaustausch mit Berlin gesprochen.

Beitz, der mehrere Angehörige in Mitteldeutschland hat, hat, wie wir uns auch vorher abgestimmt hatten, sehr offen und drastisch über die menschliche Seite der Teilung Deutschlands gesprochen. Chruschtschow habe nicht widersprochen, zu Boden geblickt und lediglich erklärt, hierüber sollten wir mit der „DDR" sprechen. Die „DDR" habe er in anderem Zusammenhang als ein groß gewordenes Kind bezeichnet, das nicht mehr so leicht zu gängeln sei, ohne daß es rabiat werde.

Im Laufe der Lagedarstellung aus seiner Sicht habe Chruschtschow de Gaulle, Macmillan und andere westliche Staatsmänner zum Beweis dafür zitiert, daß wir von diesen nichts zu erwarten hätten.

Im wirtschaftlichen Teil des Gesprächs habe Chruschtschow wieder die groBen Möglichkeiten beschworen, die ein Zusammenwirken des sowjetischen Menschenpotentials und unseres „know how“ bedeuten würde.

Zur Röhrenfrage ${ }^{6}$ habe er sich dahin geäußert, die Engländer und Schweden hätten zwar Röhrenangebote gemacht ${ }^{7}$, die Sowjetunion gedenke aber nicht, darauf einzugehen. Sie werde sich in dieser Beziehung selbständig machen. Auch das Röhrengeschäft mit unseren Firmen sei aus. Beitz hat den Eindruck, daß das Röhrenembargo doch eine Schockwirkung auf die Sowjets gehabt hat und sie die Vorstellung haben, daß das westliche Vorgehen sich in Zukunft auch auf andere Bereiche als Röhren ausdehnen könnte.

Bei Schilderung der menschlichen Härte, welche die sowjetische Politik mit sich bringe, erwähnte Beitz auch die Zahl von 9000 noch in der Sowjetunion zurückgehaltenen Deutschen. Chruschtschow habe die Tatsache, daß solche Leute sich hier noch befänden und das Problem bestehe, einfach geleugnet. ${ }^{8}$

Beitz hat den Gesamteindruck, daß Chruschtschow das Gespräch dazu benutzen wollte, um den Stand unserer Beziehungen zu entdramatisieren.

Bemerkenswert erscheint, daß er am Schluß der Unterredung die gleiche Wendung gebrauchte wie Iljitschow am 27.12.1961 bei Übergabe des sowjetischen Memorandums ${ }^{9}$ an den damaligen deutschen Botschafter ${ }^{10}$ : „Sie können jetzt mit meinen Erklärungen machen, was Sie wollen.“ Man könnte hieraus, aus dem bewußt farblos gehaltenen Kommuniqué, wie aus Chruschtschows Wunsch, das Gespräch unter vier Augen zu führen, schließen, daß es ihm -

5 Zum sowjetischen Vorschlag einer „Freien Stadt“ Berlin (West) vgl. Dok. 3, Anm. 7.

6 Zum Beschluß des Ständigen NATO-Rats vom 21. November 1962 vgl. Dok. 9, Anm. 5.

7 Vgl. dazu den Drahterlaß des Ministerialdirektors Sachs vom 23. April 1963; Abteilung III (III A6), VS-Bd. 8397; B 150, Aktenkopien 1963. Vgl. dazu ferner den Vermerk des Staatssekretärs Lahr vom 18. Mai 1963; Büro Staatssekretär, Bd. 407.

8 Vgl. dazu auch Dok. 174.

9 Für den Wortlaut des sowjetischen Memorandums vom 27. Dezember 1961 zur Deutschland- und Berlin-Frage vgl. Buldetin 1962, S. 47-52.

10 Hans Kroll. 
außer natürlich auf taktischen Nebeneffekt gegenüber unseren Alliierten darauf ankam, uns indirekt doch grundsätzliche Überlegungen zukommen zu lassen.

Beitz hat der hiesigen Presse bisher nichts mitgeteilt. Er hatte zunächst auch mir gegenüber Hemmungen, sich über den Inhalt des Gesprächs mit Chruschtschow überhaupt zu äußern, und bittet bei etwaiger Unterrichtung unserer Alliierten um strengst vertrauliche Behandlung. ${ }^{11}$

[gez.] Scholl

Ministerbüro, VS-Bd. 8419

\section{8}

\section{Aufzeichnung des Ministerialdirektors Jansen}

\section{A 3-82.00/94.07/1036/63 VS-vertraulich}

15. Mai $1963^{1}$

Betr.: Französische Einstellung zu den Problemen der Atombewaffnung der westlichen Allianz hier: Äußerungen von Informationsminister Peyrefitte am 9. Mai 1963 in Bonn

Der französische Informationsminister Peyrefitte hat sich bei den deutschfranzösischen Besprechungen über Informationsfragen am 9. und 10. Mai 1963 in Bonn wie folgt geäußert:

A. Auseinandersetzung mit den Gegnern der französischen Atomstreitmacht Gegen die französische Atomstreitmacht würden im wesentlichen drei Einwände erhoben: Sie sei 1 . lächerlich unbedeutend, 2. ruinös, 3. überflüssig. ${ }^{2}$

Hierzu sei zu sagen:

1) Die französische Atomstreitmacht lächerlich unbedeutend?

Wenn die französische Atomstreitmacht eine echte Angriffswaffe (force de frappe) werden solle, wie ihre Gegner behaupteten, wäre sie in der Tat lächerlich unbedeutend und praktisch nicht verwendbar. Sie solle aber eine reine Defensivwaffe, eine „force de dissuasion“ sein. Als solche sei sie stark genug: 1966 werde sie über 50 Bomber „Mirage IV“ mit A-Bomben verfügen, von denen jede die dreifache Kraft einer Hiroshima-Bombe habe (1. Generation). Diese Atomstreitmacht werde ausreichen, um notfalls 40-50 Millionen Men-

11 Zur Unterrichtung des Staatssekretärs Lahr durch den Generalbevollmächtigen der Firma Krupp vgl. die Aufzeichnung des Ministerialdirektors Sachs vom 31. Mai 1963; Abteilung III (III A 6), VS-Bd. 295; B 150, Aktenkopien 1963.

1 Die Aufzeichnung wurde von Legationsrat I. Klasse Lahusen konzipiert.

2 Zu dieser Einschätzung der „force de frappe“ vgl. auch den Drahtbericht des Botschafters Blankenhorn, Paris, vom 14. Juni 1963; Abteilung I (I A 1), VS-Bd. 136; B 150, Aktenkopien 1963. 
schen $^{3}$ zu vernichten. Ein solcher Einsatz lohne sich für keine Regierung; Frankreich erlange daher mit seiner Atomstreitmacht die Sicherheit, nicht angegriffen zu werden. Im Jahre 1970 werde die 2. Generation (Raketen mit H-Bomben) einsatzfähig sein.

2) Die französische Atomstreitmacht ruinös?

Im Haushaltsjahr 1963 werde Frankreich für Atomwaffenforschung und Fabrikation der beiden Generationen seiner Atomwaffen nur 13\% der gesamten französischen Militärausgaben aufbringen müssen. Der Anteil der Ausgaben für Atomwaffen an den allgemeinen Militärausgaben werde in den nächsten Jahren auf höchstens $25 \%$ steigen. Jedoch würden durch die Atombewaffnung in zunehmendem Maße Soldaten eingespart bzw. deren Dienstzeiten herabgesetzt werden können. Hierdurch werde die Wirtschaft neue Antriebe erhalten. Bereits heute wirke sich die Atomwaffenproduktion belebend auf andere Wirtschaftszweige aus.

3) Die französische Atomstreitmacht überflüssig?

Die französische Regierung hege keinerlei Zweifel an der Bereitschaft der gegenwärtigen amerikanischen Regierung, den Bereich der Verteidigungsgemeinschaft des Westens notfalls mit Atomwaffen zu verteidigen. Niemand könne aber heute schon sagen, wie der Nachfolger Präsident Kennedys handeln werde. Man müsse berücksichtigen, daß die leitenden Persönlichkeiten einem immer stärker werdenden Druck der öffentlichen Meinung ihrer Länder ausgesetzt seien, deren künftige Strömungen sich schlechterdings nicht voraussehen ließen. Im übrigen könne auch nicht für alle Zukunft verbindlich festgestellt werden, daß die amerikanischen und die europäischen Interessen immer umbedingt gleichgelagert sein müßten. Die gegenwärtige Situation der Abhängigkeit Europas von den USA dürfte daher nicht ewig aufrechterhalten bleiben. Der Aufbau der französischen Atomstreitmacht diene dem europäischen Interesse: Eines Tages werde Europa eine gemeinsame Außen- und Verteidigungspolitik haben. Dann sei der Zeitpunkt für die Aufstellung einer gemeinsamen europäischen Atomstreitmacht gekommen, als deren Embryo die französische Atomstreitmacht angesehen werden könne.

\section{B. NATO-Atomstreitmacht unter deutscher Beteiligung}

Die französische Regierung habe gegen die Aufstellung einer interalliierten Atomstreitmacht der NATO, insbesondere gegen eine deutsche Beteiligung daran, nichts einzuwenden. Die Bundesrepublik werde durch ihre Beteiligung an einer internationalen Atomstreitmacht in keiner Weise an der Durchführung eigener Programme gehindert, die sie ohnehin nicht aufstellen könne, da sie auf die Fabrikation von Atomwaffen verzichtet habe. ${ }^{4}$ Ihre Beteiligung sei für sie vielmehr der einzige Weg, um ein gewisses Mitspracherecht beim Einsatz von Atombomben zu erhalten.

Frankreich, dessen Ausgangspunkt ein ganz anderer sei als der der Bundesrepublik, wolle sich an der interalliierten Atomstreitmacht nicht beteiligen,

3 Die Wörter „40-50 Millionen Menschen“ wurden von Staatssekretär Carstens hervorgehoben. Dazu handschriftliche Randbemerkung: "Wenn sie ihr Ziel erreicht. Das ist sehr zweifelhaft."

4 Zum Verzicht der Bundesrepublik auf die Produktion von atomaren, biologischen und chemischen Waffen vgl. Dok. 37, Anm. 14. 
sondern seine eigenen Pläne weiterverfolgen. ${ }^{5}$ Man müsse sich im übrigen auch fragen, ob die interalliierte Atomstreitmacht nicht nur dem Zweck diene, das fortbestehende amerikanische Monopol für den Einsatz von Atomwaffen zu bemänteln.

Hiermit über den Herrn Staatssekretär ${ }^{6}$ dem Herrn Minister ${ }^{7}$ mit der Bitte um Kenntnisnahme vorgelegt. Abteilung II und der Planungsstab haben Doppel erhalten.

Jansen

Abteilung I (I A 3), VS-Bd. 38

169

\section{Vermerk des Vortragenden Legationsrats I. Klasse Luedde-Neurath}

II 5-82.01/94.28-674/63 VS-vertraulich

16. Mai 1963

Betr.: Ungarn-Verhandlungen

Vorbehaltlich einer Niederschrift über den Reiseverlauf, die II 5, V 1 und V 2 gemeinsam vorlegen ${ }^{1}$, wäre stichwortartig folgendes festzuhalten:

Unsere Aufnahme war sehr freundlich. Vorsitzender der ungarischen Seite war Legationsrat Szöke (Unterabteilungsleiter in einer der beiden politischen Unterabteilungen Europa). Am ersten Verhandlungstag (10.5.) baten die Ungarn, die neuen deutschen Vorschläge vorzulegen, da von ungarischer Seite ja bereits erklärt sei, daß sie unseren Entwurf vom 4 . April ${ }^{2}$, insbesondere die Einbeziehung Berlins als nicht akzeptabel bezeichnet hätten. Ich entgegnete, daß wir gekommen seien, um eine Formel für die Einbeziehung Berlins zu finden $^{3}$, und im übrigen beauftragt seien, die von Ungarn erwähnten Varianten entgegenzunehmen.

$5 \mathrm{Zu}$ den verteidigungspolitischen Vorstellungen Frankreichs vgl. bereits Dok. 37 und Dok. 143; weiter Dok. 177.

Vgl. dazu ferner die Aufzeichnung des Legationsrats I. Klasse Pfeffer vom 9. April 1963; Büro Staatssekretär, Bd. 382.

6 Hat Staatssekretär Carstens am 17. Mai 1963 vorgelegen.

7 Hat Bundesminister Schröder am 17. Mai 1963 vorgelegen.

1 Zu den vom 10. bis 15. Mai 1963 in Budapest geführten Verhandlungen mit Ungarn vgl. auch die Aufzeichnung des Ministerialdirektors Krapf vom 27. Mai 1963; Abteilung V (V 2); VS-Bd. 218; B 150, Aktenkopien 1963.

Zur Vorbereitung der Verhandlungen vgl. bereits Dok. 154.

2 Am 4. April 1963 übersandte Ministerialdirektor Krapf den Entwurf eines deutsch-ungarischen Briefwechsels über die beiderseitige Errichtung von Handelsvertretungen an den Leiter des ungarischen Außenhandelsbüros in Frankfurt/Main, Buzás. Vgl. dazu den Vermerk des Ministerialdirektors Krapf vom 4. April 1963; Abteilung V (V 2), VS-Bd. 218.

3 Zur Einbeziehung von Berlin (West) in die angestrebte Vereinbarung vgl. Dok. 154. 
Herr Szöke stellte darauf scharf heraus, daß jede Einbeziehung Berlins in den Briefwechsel über die Handelsvertretungen für die ungarische Regierung unannehmbar sei. ${ }^{4}$

Jedoch sei die ungarische Regierung bereit, in Verhandlungen über ein Handelsabkommen über irgendeine Einbeziehung Berlins zu sprechen. Diese Bereitschaft bitte er deutscherseits umso höher zu bewerten, als Ungarn zur Zeit keinen Vertrag mit der Bundesrepublik habe, in dem Westberlin einbezogen sei.

In einem Briefwechsel über die Handelsvertretungen sei aber das abgelaufene Zahlungsprotokoll ${ }^{5}$ materiell überhaupt nicht unterzubringen. Ich brachte darauf zum Ausdruck, daß wir dann eigentlich wieder abfahren könnten, daß wir aber auch die einzelnen Punkte unseres Entwurfs vom 4. April im Hinblick auf etwaige ungarische Varianten durchgehen könnten, wobei dann die Frage der Einbeziehung Berlins erst am Ende auftauchen würde.

Herr Szöke war damit einverstanden, erklärte aber, daß die Zusammenfassung vom 21.9. $1962^{6}$ für die ungarische Seite ein wohlüberlegter Kompromiß gewesen sei, den man ungarischerseits jetzt als hinfällig betrachte. Man sollte daher den Entwurf vom 21.9. anhand der ungarischen Vorschläge vom 20.9.7 und unserer Vorschläge vom 4. April 1963 durchgehen. Dies begann am 2. Verhandlungstag (1.5.), wobei wir die deutsche Auffassung über die Rechtsnatur der Handelsvertretungen zum Ausdruck brachten. Der dritte Verhandlungstag (Montag) galt der Besprechung verschiedener juristischer Punkte ohne Teilnahme der Vorsitzenden. Am 3. Verhandlungstag abends gaben wir den Ungarn eine Gegeneinladung, bei der Herr Szöke und ich in liebenswürdigẹ Form, aber äußerster sachlicher Schärfe eine politische Auseinandersetzung hatten (gesonderte Aufzeichnung folgt). Am folgenden Tage zeigte die ungarische Seite Bereitschaft, sich unsere Gedanken über eine Einbeziehung Berlins darlegen zu lassen. Unter Hinweis auf die Vertraulichkeit erläuterten wir die polnische Lösung ${ }^{8}$ und eine evtl. mögliche andere Variante.

Herr Szöke erwiderte darauf, daß er unter rigoroser Weisung seiner Regierung Berlin nicht in das Vertretungsabkommen einbeziehen könne, daß er aber doch glaube, daß sich eine Verklammerung finden lasse, wenn etwas zu verklammern sei, d. h. wenn Handelsabkommen und Briefwechsel über die

4 Der Vorsitzende der ungarischen Verhandlungsdelegation, Szöke, bemerkte dazu, „daß man sich beim Abschluß des langfristigen Handelsabkommens über die Frage des räumlichen Geltungsbereichs (d. h. die Einbeziehung Berlins) werde einigen können, sofern die deutsche Seite einen für die ungarische Regierung annehmbaren Formulierungsvorschlag unterbreiten könne. Er habe jedoch ,rigorose Weisung zu erklären, daß in die Vereinbarung über die Errichtung von Handelsvertretungen keine irgendwie geartete Klausel aufgenommen werden könne, aus der hervorgehe, daß Berlin als ein Bestandteil der Bundesrepublik Deutschland angesehen werde und die Bundesregierung irgendeine Jurisdiktion über Berlin ausübe." Vgl. die Aufzeichnung des Ministerialdirektors Krapf vom 27. Mai 1963; Abteilung V (V 2), VS-Bd. 215; B 150, Aktenkopien 1963.

5 Zum Zahlungsprotokoll zwischen der Bundesrepublik und Ungarn vom 27. Oktober 1955 und der darin enthaltenen Berlin-Klausel vgl. Dok. 154, Anm. 8.

$6 \mathrm{Vgl}$. Abteilung V (V 2), VS-Bd. 218.

$7 \mathrm{Vgl}$. Abteilung V (V 2), VS-Bd. 218.

8 Zur Einbeziehung von Berlin (West) in das Abkommen mit Polen vom 7. März 1963 über den Handels- und Seeschiffahrtsverkehr sowie den Austausch von Handelsvertretungen vgl. Dok. 183, besonders Anm. 3. 
Handelsvertretungen gleichzeitig in Kraft treten würden. Dabei blieb noch offen, ob eine Verklammerung durch ein Mantelprotokoll den Ungarn akzeptabel erscheinen oder eine andere abstrakte Verweisungsklausel in beiden Abmachungen die Einbeziehung Berlins sichern könne.

Eine ernste Meinungsverschiedenheit besteht zur Zeit noch darin, daß die ungarische Seite den Ausdruck ,beschränkte konsularische Befugnisse“ aufgenommen sehen möchte. Sie war jedoch bereit, eine konsularische Generalklausel (6a des Entwurfs vom 21.9. 1962) wegzulassen.

An einer Ziffer über die geplante Fortentwicklung der Beziehungen ist den Ungarn nach wie vor sehr gelegen. ${ }^{9}$

Abteilung V (V 2), VS-Bd. 218

\section{Gespräch des Bundeskanzlers Adenauer mit Professor Kissinger, Harvard University}

Z A 5-56-A/63 geheim

17. Mai $1963^{1}$

Der Herr Bundeskanzler empfing am 17. Mai 1963 um 12.00 Uhr Professor Kissinger zu einem Gespräch, bei dem außerdem VLR I Dr. Osterheld zugegen war.

Auf die Frage des Herrn Bundeskanzlers, ob sich in Amerika bereits der Wahlkampf ${ }^{2}$ bemerkbar mache, erwiderte Professor Kissinger, bis vor einigen Wochen hätte man erwartet, daß Rockefeller Kandidat der republikanischen Partei würde. Dessen Wiederverheiratung ${ }^{3}$ habe die Situation allerdings etwas komplizierter gemacht. Er sei jedoch sicher, daß von nun an und sicherlich von Sommer an der Wahlkampf sich mehr und mehr bemerkbar machen werde.

Der Herr Bundeskanzler erkundigte sich dann nach den Aussichten Goldwaters, die Mr. Kissinger sehr schlecht beurteilte. Die einzige Möglichkeit für eine Nominierung Goldwaters bestünde, wenn alle anderen Kandidaten der Republikaner der Auffassung seien, daß Kennedy unschlagbar sei.

9 Zum Fortgang der Verhandlungen mit Ungarn vgl. Dok. 332.

1 Durchschlag.

Die Gesprächsaufzeichnung wurde vom Vortragenden Legationsrat Kusterer am 20. Mai 1963 gefertigt.

2 Die nächsten Wahlen in den USA fanden am 3. November 1964 statt.

3 Nelson A. Rockefeller ließ sich 1962 scheiden und heiratete am 4. Mai 1963 Margaretta Fidler Murphy. Zur Person von Rockefeller vgl. Dok. 117, Anm. 17.

Die Nominierung zum Präsidentschaftskandidaten der Republikanischen Partei für die Wahl am 3. November 1964 verlor er gegen Senator Goldwater, Arizona. 
Der Herr Bundeskanzler fragte dann, ob Kennedy hundertprozentige Aussicht auf Wiederwahl habe.

Professor Kissinger erklärte, der Präsident habe natürlich immer große propagandistische Möglichkeiten. Die Popularität Kennedys bezeichnete er als vergleichbar mit der eines Filmstars, wodurch starke Schwankungen jederzeit möglich seien. Er glaube, daß ein sehr energischer republikanischer Wahlkampf, insbesondere wenn noch außenpolitische Krisen hinzukämen, für Kennedy gefährlich werden könnte. Kennedy werde entweder mit einer großen Mehrheit oder überhaupt nicht wiedergewählt.

Der Herr Bundeskanzler bezeichnete diese Ungewißheit als ein unbehagliches Gefühl sowohl für Kennedy als in der Politik überhaupt. Der amerikanische Präsident habe doch einen ungeheueren politischen Einfluß auf die Welt.

Professor Kissinger fragte, ob der Herr Bundeskanzler glaube, daß es für die Bundesrepublik einen großen Unterschied ausmache, wer Präsident werde.

Der Herr Bundeskanzler erwiderte, das könne man so einfach nicht sagen. Jedenfalls sei der Ausgang der Wahlen für alle Europäer eine Frage größter Bedeutung, denn das Schicksal Europas hänge stark von der Persönlichkeit des amerikanischen Präsidenten ab.

Professor Kissinger erklärte, er glaube, daß jeder Präsident an einem sehr engen Verhältnis mit Europa stets interessiert sein werde.

Der Herr Bundeskanzler fragte, ob nach Kissingers Auffassung der Isolationismus erledigt sei.

Professor Kissinger bestätigte dies und wies darauf hin, daß die isolationistische Partei, nämlich die Republikaner, jetzt der Regierung Vorwürfe mache, weil sie das Verhältnis zu den Europäern getrübt habe. Natürlich könnten jederzeit Fehler gemacht und eine falsche Politik verfolgt werden, doch glaube er nicht an die Möglichkeit einer isolationistischen Politik.

Der Herr Bundeskanzler fragte, ob die amerikanischen Wähler nicht stimmungsmäßig sehr beeinflußbar seien.

Professor Kissinger erwiderte, die amerikanischen Wähler, insbesondere im mittleren Westen, hätten an Außenpolitik kein Interesse, und es könnte natürlich sein, daß jemand dies ausnutze. Er kenne aber in der amerikanischen Führungsschicht niemand, der dies jemals seit Kriegsende versucht habe.

Der Herr Bundeskanzler bemerkte, bei der ungeheuer großen Bedeutung des amerikanischen Präsidenten sei eine Amtsperiode von vier Jahren doch sehr kurz. Der mit einem Präsidentenwechsel verbundene Wechsel in der Regierungsmethode sei dabei auch zu berücksichtigen. Er glaube, daß diese Tatsache auch bei de Gaulles Überlegungen eine Rolle spiele. ${ }^{4}$

Professor Kissinger war der Auffassung, daß man doch mit acht Jahren rechnen könnte, da es schwierig sei, einen amtierenden Präsidenten zu schlagen. Im vorliegenden Falle handle es sich wegen der Jugend, der Religion ${ }^{5}$ und des

4 Vgl. dazu auch die Äußerungen des Staatspräsidenten de Gaulle zu Bundeskanzler Adenauer; Dok. 37.

5 Präsident Kennedy war Katholik und zum Zeitpunkt des Gesprächs 46 Jahre alt. 
persönlichen Stils Präsident Kennedys um einen Sonderfall, wo die Möglichkeit einer starken Popularitätsschwankung sehr viel größer sei als bei Präsident Eisenhower. Ein typischer Präsident könne aber als für acht Jahre gewählt betrachtet werden.

Der Herr Bundeskanzler bezeichnete dies als für die Europäer beruhigend.

Professor Kissinger wies noch darauf hin, daß die Führungsschicht der Vereinigten Staaten auf außenpolitischem Gebiet nur eine relativ beschränkte Personenzahl umfasse. Wenn man z. B. an den Council on Foreign Relations ${ }^{6}$ denke, so werde ein Mann wie McCloy immer Einfluß haben, ob er nun in der Regierung sitze oder nicht, und bei einer Neubesetzung werde ein Mann wie McCloy oder $\mathrm{Clay}^{7}$ immer gefragt. Man könnte sich natürlich vorstellen, daß bei technischen Vorschlägen wie z. B. der multilateralen Streitkraft gewisse Schwankungen vorhanden seien. Wenn man aber von dem Verhältnis zur NATO oder zur Bundesrepublik spreche, könne er sich derartige Schwankungen nicht vorstellen.

Der Herr Bundeskanzler wies darauf hin, daß auch Schwankungen in entscheidenden technischen Fragen von großer Bedeutung seien.

Auf die Frage Professor Kissingers, welche Meinung der Herr Bundeskanzler hinsichtlich der multilateralen Streitmacht vertrete, erwiderte der Herr Bundeskanzler, man müsse hier natürlich unterscheiden. Für ihn als Deutschen sei die Antwort sehr einfach gewesen, und zwar gleichgültig, ob der Vorschlag technisch schon völlig durchdacht sei oder nicht. Für Deutschland sei es ausschlaggebend, den Anschluß an die Vereinigten Staaten, an die Entwicklung, nicht zu verpassen. ${ }^{8}$ (Dies könnten sich aber Länder wie England oder Frankreich leichter erlauben.)

Professor Kissinger fragte, ob der Herr Bundeskanzler also an dem Projekt interessiert sei, weil es von Amerika vorgeschlagen worden sei.

Der Herr Bundeskanzler bestätigte dies. (Im übrigen wisse er auch nicht, ob die Bundesrepublik genügend Sachverständige habe, um sich wirklich ein Urteil erlauben zu können.)

Professor Kissinger fragte dann, ob der Herr Bundeskanzler den Eindruck habe, daß eine Trübung des Verhältnisses mit Amerika nach den Ereignissen im Januar eingetreten sei.

Der Herr Bundeskanzler erklärte, eine solche Trübung sei offensichtlich eingetreten $^{9}$, doch verstehe er ganz ehrlich gesagt überhaupt nicht, warum dies gekommen sei. Seiner Ansicht nach sei es von de Gaulle sicherlich nicht klug gewesen, die Pressekonferenz am 14. Januar zu halten. Das Datum für sein,

6 Der Council on Foreign Relations ist ein 1921 gegründeter einflußreicher Kreis von Politikern, Wissenschaftlern, Geschäftsleuten und Journalisten zur Befassung mit außenpolitischen Problemen.

7 Zu Lucius D. Clay vgl. Dok. 58, Anm. 3.

8 Zur deutschen Haltung zum Projekt einer integrierten Atomstreitmacht der NATO vgl. Dok. 82, Anm. 10. Vgl. auch Dok. 156.

9 Zur amerikanischen Reaktion auf den deutsch-französischen Vertrag vom 22. Januar 1963 vgl. besonders Dok. 88. 
des Herrn Bundeskanzlers, Zusammentreffen mit General de Gaulle sei jedoch schon im Dezember festgelegt worden ${ }^{10}$, und er hätte es für politisch unklug gehalten, nun zu de Gaulle zu sagen, weil er diese Pressekonferenz gehalten habe, werde er (der Herr Bundeskanzler) nicht nach Paris kommen. Im übrigen habe er auch den Eindruck, daß de Gaulles Pressekonferenz in erster Linie gegen Macmillan und nicht gegen die Vereinigten Staaten gerichtet gewesen sei. Er erläuterte dann unter dem Siegel der Verschwiegenheit die Darlegung de Gaulles über die Ereignisse in Rambouillet und Nassau. ${ }^{11}$

Professor Kissinger meinte, ausländische Regierungen schienen niemals glauben zu wollen, daß irgendetwas improvisiert werden könnte. Er habe nicht den Eindruck, daß seine Regierung mit festen Vorstellungen nach Nassau ${ }^{12}$ gegangen sei.

Der Herr Bundeskanzler erwiderte, er spreche auch nicht von der amerikanischen Regierung, der dieser Vorwurf im übrigen auch von de Gaulle nicht gemacht werde. Er spreche vielmehr von Macmillan, der ja zuerst den ersten und zweiten Vorschlag Kennedys ${ }^{13}$ abgelehnt und dann seinen Polaris-Vorschlag gemacht habe. Er könne sich nicht vorstellen, daß Macmillan bei der Unterhaltung in Rambouillet ${ }^{14}$ zwei Tage vorher, die ja auch nukleare Waffen zum Thema gehabt habe, noch keinerlei derartigen Absichten gehegt habe. Für Kennedy und das State Department sei Macmillans Vorschlag, das glaube er, sicherlich überraschend gekommen.

Auf die Frage von Mr. Kissinger, ob der Herr Bundeskanzler glaube, daß de Gaulles Verhalten durch Nassau ausgelöst worden sei, erwiderte der Herr Bundeskanzler, de Gaulles Verhalten sei durch Rambouillet und Nassau ausgelöst worden. Er berichtete dann über sein Gespräch mit General de Gaulle in Paris am 21.1.6315 und die Bemühungen um eine Beilegung der französisch-britischen Krise. Diese Bemühungen seien aber durch eine überdimensionale Dummheit am 29. Januar zunichte gemacht worden ${ }^{16}$, da Großbritannien und andere darauf bestanden hätten, den Bericht von der Kommission auch für Großbritannien anzufordern, was Couve de Murville abgelehnt habe. ${ }^{17}$ Hierbei habe Couve de Murville auch insofern recht gehabt, als die Sechs von der Kommission den Bericht hätten anfordern müssen, der dann Großbritannien zugänglich gemacht worden wäre. Nur diesem Verfahren

10 Vgl. dazu Dok. 57, Anm. 11.

11 Zu den Äußerungen des Staatspräsidenten de Gaulle zu Rambouillet und Nassau vgl. Dok. 37 und Dok. 43.

12 Zum Treffen zwischen Präsident Kennedy und Premierminister Macmillan vom 18. bis 21. Dezember in Nassau vgl. Dok. 2, Anm. 2.

13 Bei den ersten beiden Vorschlägen des Präsidenten Kennedy handelte es sich um die Raketen „Hound Dog“ und „Honest John“. Zur Diskussion in Nassau und zur britischen Entscheidung für Polaris vgl. Macmillan, End of the Day, S. 356-359. Vgl. dazu auch Schlesinger, Thousand Days, S. $860 \mathrm{f}$.

14 Zu den Gesprächen des Premierministers Macmillan mit Staatspräsident de Gaulle am 15./16. Dezember 1962 vgl. Dok. 12, Anm. 6.

15 Vgl. Dok. 37.

16 Zum Scheitern eines britischen Beitritts zur EWG am 29. Januar 1963 vgl. Dok. 60.

17 Vgl. dazu auch Dok. 85, besonders Anm. 4. 
habe General de Gaulle dem Herrn Bundeskanzler gegenüber am 22. 1. ${ }^{18}$ auch zugestimmt.

Mr. Kissinger fragte dann den Herrn Bundeskanzler, ob er glaube, daß England wirklich habe beitreten wollen oder ob England vielleicht froh gewesen wäre, daß die Angelegenheit auf diese Weise zu einem Ende gekommen sei.

Der Herr Bundeskanzler erwiderte, England habe ja früher schon zweimal einen Beitritt abgelehnt. ${ }^{19}$ Es sei schwer festzustellen, was England wirklich wolle.

Mr. Kissinger sagte dann, im vergangenen Sommer habe der Herr Bundeskanzler über das Fernsehen zugunsten einer Assoziierung und gegen eine Vollmitgliedschaft Englands gesprochen. Er fragte, ob der Herr Bundeskanzler immer noch dieser Auffassung sei.

Der Herr Bundeskanzler erwiderte, wenn Großbritannien eine Assoziierung wolle, wäre er zweifellos damit einverstanden. Im Augenblick sehe er aber überhaupt schwarz mit internationalen Verhandlungen. Bei der GATT-Konferenz in Genf $^{20}$, an der 73 Nationen beteiligt seien, sei der Anfang damit gemacht worden, daß die tropischen Länder für tropische Produkte einen Nulltarif verlangt hätten. Herter habe dies stark unterstützt. All das aber sei wohl nicht sehr durchdacht, denn wenn man z. B. Kaffee nehme, so sei festzustellen, daß Kaffee eine wesentliche Steuerquelle in Deutschland sei. Selbst wenn die Bundesrepublik bereit wäre, einer Senkung der Zölle auf Null zuzustimmen, müßte sie zunächst prüfen, wie sie die dadurch entstehende Haushaltslücke füllen könnte. Dasselbe gelte für Tabak. $\mathrm{Zu}$ beachten sei auch, daß man die Wirtschaft der Entwicklungsländer allmählich in anderer Weise stärken müßte, denn wenn Kaffee nunmehr zollfrei eingeführt werden könnte, würde jedes Entwicklungsland anfangen, Kaffee zu produzieren.

Professor Kissinger sagte dann, während seiner Amtszeit sei der Herr Bundeskanzler immer für das engste Verhältnis der Bundesrepublik zum Westen eingetreten. Er fragte dann, ob der Herr Bundeskanzler bei einem Vergleich der heutigen Situation mit der Zeit unter Dulles sagen würde, daß dieses Verhältnis sich weiter gestärkt habe oder schwächer geworden sei.

Der Herr Bundeskanzler kam zunächst auf sein persönliches Verhältnis zu Dulles zu sprechen, das so eng gewesen sei, daß etwas derartiges nicht wiederkommen könnte. Es sei für Deutschland ein großes Glück gewesen, daß Dulles in Deutschland so großes Vertrauen gesetzt und auch das Vertrauen Eisenhowers gehabt habe.

Professor Kissinger fragte dann, ob das strukturelle Verhältnis der Bundesrepublik zu den Vereinigten Staaten sich hoffnungsgemäß entwickelt habe oder ob der Herr Bundeskanzler hier Schwierigkeiten sehe.

Der Herr Bundeskanzler erwiderte, dieses Verhältnis sei schwieriger geworden. Auch das Verhältnis mit NATO sei schwieriger geworden. Auf die Frage nach dem Grund dafür antwortete der Herr Bundeskanzler, er könne nur mit

18 Vgl. dazu Dok. 43.

19 Vgl. dazu Dok. 52, Anm. 16.

20 Zur Ministerkonferenz des GATT vom 16. bis 21. Mai 1963 in Genf vgl. Dok. 164, Anm. 5. 
Stikkers Worten antworten, der ihm einmal erklärt habe, er wisse nie, ob ein NATO-Botschafter in seiner persönlichen Eigenschaft oder im Auftrag seiner Regierung spreche, denn es passiere, daß ein Botschafter am Mittwoch erkläre, seine Erklärung vom Montag stelle nur seine persönliche Meinung dar.

Auf die Frage von Mr. Kissinger, ob sich dies im vergangenen Jahr nicht geändert habe, erwiderte der Herr Bundeskanzler, Stikker sei nicht dieser Auffassung. Im übrigen werde Stikker ja auch schlecht behandelt. Wenn Stikker gestorben wäre ${ }^{21}$, wäre er dafür eingetreten, daß die Amerikaner den Generalsekretär stellen.

Auf den Einwurf Mr. Kissingers, daß es psychologisch sehr schwierig wäre, den Oberbefehlshaber und den Generalsekretär von Amerika aus zu stellen, erwiderte der Herr Bundeskanzler, dann wüßte man wenigstens, woran man sei. Spaak habe nichts erreicht, und der arme Stikker quäle sich zu Tode. Holland sei ein relativ kleines Land, so daß Stikker von dort eine natürliche Unterstützung nicht erhalten könnte. Besonders aber wäre er dafür, daß die Vereinigten Staaten, die die höchste Verantwortung trügen, dies auch klar zum Ausdruck brächten. Es liege eine ungeheuere erzieherische Wirkung in der Tatsache, daß man sichtbar die höchste Verantwortung trage.

Mr. Kissinger kam dann auf das bilaterale amerikanisch-deutsche Verhältnis zu sprechen und sagte, manchmal könne man lesen, daß hier in der Bundesrepublik der Eindruck herrsche, als klappe die Verständigung nicht mehr so wie früher.

Der Herr Bundeskanzler bemerkte, er sei immer der Meinung gewesen, daß Professor Grewe nicht der richtige Mann für Washington gewesen sei ${ }^{22}$, während er in Paris wirklich am richtigen Platz zu sein scheine. Das Verhältnis mit Amerika habe sich unter Herrn Knappstein, der dort wohl an richtiger Stelle sitze, gebessert. Es komme doch sehr darauf an, welche deutsche Persönlichkeit den Kontakt herstelle.

Mr. Kissinger kam noch einmal auf den deutsch-französischen Vertrag zurück und bemerkte, in einigen kleineren Ländern habe dieser Vertrag Anlaß zu der Befürchtung gegeben, daß es dabei um einen deutsch-französischen Versuch für eine Hegemonialstellung innerhalb der Sechs gegangen sei.

Der Herr Bundeskanzler bemerkte, diese Leute verstünden von der Geschichte nichts. Gerade bei Nachbarvölkern spiele die Tradition eine sehr große Rolle. Seit Karl V. habe es immer Gegensätze zwischen Deutschland und Frankreich gegeben. Nunmehr aber sehe die Karte Europas anders aus.

Mr. Kissinger sagte, er sage seinen amerikanischen Freunden immer, daß er es persönlich als eine Tragödie empfinden würde, wenn die deutsch-französische Rivalität künstlich wiedergeschaffen würde. Er sei auch immer beunru-

21 Zur Erkrankung des NATO-Generalsekretärs Stikker im Herbst 1962 vgl. STIKker, Bausteine, S. 448-450.

22 Zu den Ereignissen des Frühjahrs und Sommers $1962 \mathrm{im} \mathrm{Zusammenhang} \mathrm{mit} \mathrm{der} \mathrm{Abberufung} \mathrm{des}$ Botschafters Grewe aus Washington vgl. GREWE, Rückblenden, S. 548-574. Vgl. dazu auch OsTERHELD, Kanzlerjahre, S. 106.

Grewe war seit dem 1. November 1962 Ständiger Vertreter bei der NATO in Paris. 
higt, wenn er Dinge sehe, die eine Spitze gegen Frankreich hätten. Die Fragmentierung Europas habe er schon immer als tragisch empfunden.

Der Herr Bundeskanzler wies darauf hin, daß die Satellitenstaaten bis weit nach Europa hineinreichten. Der politische Druck werde anhalten, und wenn Deutschland und Frankreich zusammenstünden, könnten sie diesem Druck besser widerstehen. De Gaulle habe ihm selbst einmal gesagt, er habe keine Lust, eines Morgens mit der Nachricht geweckt zu werden, daß die Russen am Rhein stünden. Jede Außenpolitik müsse auf den Interessen des eigenen Landes aufgebaut sein. Es liege im Interesse Frankreichs, Deutschland frei und im Bündnis mit Frankreich stark zu sehen, um damit einen Damm gegen die Sowjetunion zu schaffen, der möglichst stark sei.

Mr. Kissinger sagte dann, manchmal werde in Amerika das Argument laut, es sei eine Illusion zu glauben, Frankreich und Deutschland könnten ein ausreichend starker Damm sein.

Der Herr Bundeskanzler verwies darauf, daß Frankreich und Deutschland zusammen heute etwa 103 Millionen Menschen zählten. Wenn sie gemeinsam nicht stark genug seien, so seien sie bestimmt noch weniger stark, wenn sie Krach miteinander hätten.

Mr. Kissinger fragte dann, ob nach Auffassung des Herrn Bundeskanzlers in der zukünftigen innenpolitischen Situation Frankreichs und der Bundesrepublik die politische Linie weiterverfolgt werde, die der Herr Bundeskanzler als historische Leistung niedergelegt habe.

Der Herr Bundeskanzler erwiderte, in einer so bewegten Zeit könne man natürlich nichts mit hundertprozentiger Gewißheit sagen. Dennoch halte er es für höchst wahrscheinlich, daß in Deutschland diese Politik weitergeführt und auch Frankreich mit der Bundesrepublik gegen Rußland stehen werde.

Mr. Kissinger sagte, solange de Gaulle an der Macht sei, sehe der Herr Bundeskanzler hier wohl kein Problem.

Der Herr Bundeskanzler sagte, de Gaulle sei an der Macht, und er hoffe, daß de Gaulle noch lange an der Macht bleibe. Man brauche sich nur einmal vorzustellen, was Frankreich vor de Gaulle gewesen sei. Wenn Frankreich nicht eine so ausgezeichnete Beamtenschaft gehabt hätte, hätte Gott weiß was passieren können. ${ }^{23}$

Mr. Kissinger bemerkte, persönlich ziehe er starke und schwierige Persönlichkeiten schwachen Jasagern vor.

Der Herr Bundeskanzler sagte, de Gaulle sei sehr klug. Einige Dinge, die de Gaulle tue, müsse man sich aus der Tatsache heraus erklären, daß de Gaulle sie sage und tue, weil die Franzosen dies gerne hätten. De Gaulle habe auch Verständnis für die Empfindungen anderer. In diesem Zusammenhang erzählte der Herr Bundeskanzler, wie er de Gaulles Einladung zweimal mit dem Hinweis abgelehnt habe, daß er Vertreter eines besiegten Landes sei. ${ }^{24}$

23 Zur instabilen innenpolitischen Lage der IV. Republik vgl. Adenauer, Erinnerungen III, S. 396400.

24 Vgl. dazu Adenauer, Erinnerungen III, S. $417 \mathrm{f}$. 
Mr. Kissinger fragte dann, ob nach Auffassung des Herrn Bundeskanzlers de Gaulle wirklich beabsichtige, die Vereinigten Staaten aus Europa zu verdrängen.

Der Herr Bundeskanzler sagte, schon ein einigermaßen vernünftiger Mensch könnte nie auf diese Idee kommen. Das sei der größte Unsinn, den es überhaupt gebe. De Gaulle befürchte nur, daß die Amerikaner Europa verlassen könnten. ${ }^{25}$

Mr. Kissinger fagte, ob der Herr Bundeskanzler diese Befürchtung teile.

Der Herr Bundeskanzler erwiderte mit dem Hinweis auf eine Frage, die er an Dulles einmal gestellt habe, ob der amerikanische Präsident auf den Knopf drücken werde, wenn die erste russische Wasserstoffbombe über New York oder Chicago explodiert sei, worauf Dulles geantwortet habe, Amerika werde dann noch tapferer kämpfen als zuvor. Er selbst habe diese Frage damals gestellt, weil er die Lage des amerikanischen Präsidenten, der mit diesem Druck auf den Knopf einen Weltbrand entfachen würde, sehr gut verstehe.

Mr. Kissinger wies darauf hin, daß ein Wasserstoffbombenangriff auf Amerika der einfachste Fall sei, wo Amerika ganz zweifellos nicht zögern würde, den Gegenschlag auszulösen. Er glaube auch nicht, daß Amerika in anderen Fällen zögern würde.

Der Herr Bundeskanzler bemerkte, es komme eben sehr auf die Psychologie des führenden Mannes an.

Mr. Kissinger sagte, ein Angriff auf die Vereinigten Staaten würde beim amerikanischen Volk zweifellos eine ganz primitive Reaktion hervorrufen.

Der Herr Bundeskanzler sagte, Amerika habe ja niemals einen Krieg im eigenen Lande gehabt, und daher könne niemand wissen, wie das Volk psychologisch auf ein solche Tatsache reagieren würde.

Mr. Kissinger bemerkte, in vielen Fragen stimme er mit der Regierung nicht überein, doch glaube er, daß das amerikanische Volk ziemlich primitiv reagieren werde. Man habe auch im Zweiten Weltkrieg gesehen, daß die amerikanischen Soldaten, von denen er nicht wisse, ob sie in der Offensive gut seien (der Herr Bundeskanzler: „Sie waren vorsichtig!"), in der Defensive jedesmal empört gewesen seien, wenn es jemand gewagt habe, sie anzugreifen. Bei einer Blockade Berlins und anderen komplizierter liegenden Fällen könnten natürlich verschiedene Strömungen auftreten, doch halte er einen Angriff auf die Vereinigten Staaten selbst als psychologisch einfachsten Fall.

Der Herr Bundeskanzler verwies auf die Japaner, die ein außerordentlich tapferes Volk seien. Dennoch hätten zwei kleine Bomben genügt. ${ }^{26}$ Niemand könne sich vorstellen, welche psychologische Wirkung der Abwurf einer Bombe auf eine Großstadt habe. Er wolle damit keinerlei Befürchtung zum

$25 \mathrm{Vgl}$. dazu auch die Aufzeichnung des Vortragenden Legationsrats Kusterer über ein Gespräch des Staatspräsidenten de Gaulle mit Bundeskanzler Adenauer am 6. September 1962; Bundeskanzleramt, AZ 21-30100 (51), Bd. 2; B 150, Aktenkopien 1962. Vgl. zu diesem Gespräch auch Adenauer, Erinnerungen IV, S. 181-184.

26 Am 6. und 9. August 1945 wurde je eine amerikanische Atombombe über den Städten Hiroshima und Nagasaki abgeworfen. Daraufhin erfolgte am 10. August ein japanisches Kapitulationsangebot, das von den Alliierten angenommen wurde. 
Ausdruck bringen, man müsse sich lediglich auch solche Gedanken einmal überlegen. Er sei im übrigen der Meinung, daß gerade aus diesem Grunde die Sowjetunion keinen Krieg beginnen werde, da sie selbst die Wirkung eines Gegenschlages auf die russische Bevölkerung nicht zu berechnen vermöchte. Die Gefahr sei seiner Ansicht nach viel größer, wenn kleinere Länder etwas Unbesonnenes unternähmen. Er glaube nicht, daß Rußland einen nuklearen Krieg riskieren werde, und Amerika werde dies ganz bestimmt nicht tun.

Mr. Kissinger erklärte, nach seiner Ansicht würden die Amerikaner den Gegenschlag mit Sicherheit führen, wenn Europa angegriffen würde.

Der Herr Bundeskanzler erklärte, wenn die Russen dessen sicher seien, würden sie auch keinen Angriff wagen. Hier liege ja die relative Sicherheit begründet, weil die große Unbekannte die Wirkung des Gegenschlags auf die Bevölkerung sei.

Zum Abschluß des Gesprächs beglückwünschte Mr. Kissinger den Herrn Bundeskanzler zur Ratifizierung des deutsch-französischen Vertrages. ${ }^{27}$

Das Gespräch endete um 13.20 Uhr.

Stiftung Bundeskanzler-Adenauer-Haus, Bestand III/79

171

\section{Gespräch des Bundesministers Schröder mit dem tanganjikanischen Botschafter Tibandebage}

Der Herr Bundesminister des Auswärtigen empfing am 17. Mai 1963 um 10.30 Uhr den Botschafter von Tanganjika zum Antrittsbesuch.

Im Laufe des Gesprächs fragte der Herr Minister den Botschafter, wie nach seiner Ansicht die früher britischen Teile Afrikas zu der Möglichkeit einer Assoziierung mit der $\mathrm{EWG}^{2}$ stünden.

Der Botschafter erklärte, bei seinem kürzlichen Deutschlandbesuch habe der Minister für Handel und Industrie die Haltung der ostafrikanischen Länder

27 Zur Einleitung des Ratifizierungsverfahrens vgl. Dok. 70, Anm. 4.

Der Bundestag beriet das Ratifizierungsgesetz in erster Lesung am 25. April 1963 und überwies die Vorlage an den Ausschuß für auswärtige Angelegenheiten. Vgl. dazu BT STENOGRAPHISche Berichte, Bd. 53, S. 3417-3445. Am 16. Mai 1963 stimmte der Bundestag dem Vertrag in dritter Lesung bei 5 Gegenstimmen und 10 Enthaltungen zu. Vgl. dazu BT STENOGRAPHISche Berichte, Bd. 53, S. 3742-3754.

1 Die Gesprächsaufzeichnung wurde vom Vortragenden Legationsrat Kusterer am 17. Mai 1963 gefertigt.

2 Zu den Beziehungen der vormals britischen Kolonien zur EWG vgl. auch Dok. 122. 
gegenüber der EWG ja schon klargestellt. ${ }^{3}$ Ursprünglich seien diese Länder aus Gründen, die damals haltbar gewesen seien, nicht an einer Assoziierung interessiert gewesen. In der letzten Zeit habe sich jedoch eine Tendenz bemerkbar gemacht, zwar weiterhin nicht um Assoziierung nachzusuchen, jedoch auf die Gelegenheit zu warten, bei der eine Art der Assoziierung gefunden werden könnte, die weniger formell wäre als etwa die Assoziierung der 18 afrikanischen Staaten ${ }^{4}$. Der Botschafter verwies auf die Wirtschaftsunion zwischen Kenia, Tanganjika und Uganda ${ }^{5}$ und deutete an, daß es Möglichkeiten einer Erweiterung dieser Union geben könnte, da eine enge Affinität dieser Länder mit Njassaland, Nordrhodesien, möglicherweise sogar Südrhodesien bestehe. Diese Affinität gebe es auch mit Ruanda und Burundi und wohl auch mit dem Kongo. ${ }^{6}$

Auf die Frage des Herrn Ministers, wie man in Afrika ein Ereignis wie die gestrige Ratifizierung des deutsch-französischen Vertrages ${ }^{7}$ bewerte, antwortete der Botschafter, persönlich begrüße er dieses Ereignis als historisch. Über die Einstellung seiner Regierung habe er allerdings im Augenblick keine genaueren Informationen.

Der Herr Minister fragte dann, ob die NATO und NATO-Probleme in Afrika auf eine Resonanz stießen und ob sie positiv oder negativ bewertet würden.

Der Botschafter antwortete, nach afrikanischer Auffassung spiele die NATO eine außerordentlich nützliche Rolle, da sie eine große Kraft darstelle, von der man vernünftigerweise hoffen könnte, daß sie ein Gegengewicht gegen eine andere große Kraft, die für die Welt gefährlich sein könnte, bilde. Negatives sei kaum zu bemerken. Lediglich beklage man sich von Zeit zu Zeit etwas über die Rassenpolitik Südafrikas und die portugiesische Apathie gegen die moderne Entwicklung ${ }^{8}$ und über die Tatsache, daß das zwar nicht ermutigt, aber von der NATO auch nicht entmutigt werde.

Die Frage nach dem Prestige, das die Vereinten Nationen in Afrika genössen, beantwortete der Botschafter dahingehend, daß dieses Prestige wachse, weil die afro-asiatischen Länder von der UNO immer stärker anerkannt würden.

Der Herr Minister fragte dann, ob sich der sowjetische und kommunistische Einfluß in Afrika in den letzten Jahren gesteigert habe.

Der Botschafter erwiderte, die russische Art des Einflusses könnte sich ent-

3 Zum Besuch des tanganjikanischen Wirtschaftsministers Clement George Kahama vom 18. bis 23. März 1963 in der Bundesrepublik vgl. Bulletin 1963, S. 502. Vgl. dazu auch Referat 418, Bd. 212.

4 Zum Assoziierungs-Abkommen mit den afrikanischen Staaten vgl. Dok. 31, Anm. 5, und Dok. 82 , Anm. 9.

5 Die Präsidenten Nyerere, Obote und Kenyatta gaben am 6. Juni 1963 auf einer Konferenz in Nairobi den Entschluß bekannt, bis Ende 1963 einen politischen Zusammenschluß Tanganjikas, Ugandas und Kenias in Form einer Ostafrikanischen Föderation zu schaffen. Vgl. AdG 1963, S. 10626 .

6 Tanganjika, Ruanda, Burundi und der Kongo schlossen am 21. März 1963 in Daressalam ein Abkommen über die Bildung einer Gemeinsamen Verwaltungskommission für die Häfen Daressalam und Kigoma. Vgl. AdG 1963, S. 10481.

7 Zur Ratifizierung des deutsch-französischen Vertrags vom 22. Januar 1963 vgl. Dok. 170, Anm. 27.

8 Zur portugiesischen Kolonialpolitik vgl. Dok. 122, Anm. 5. 
wickelt haben, hätte es aber in Wirklichkeit nicht getan. Dies sei zurückzuführen auf die Kontakte, die von sowjetischer Seite mit den afrikanischen Ländern aufgenommen worden seien. Dadurch sei ein Austausch von Personen in beiden Richtungen eingetreten und habe zu der Erkenntnis geführt, daß die Worte nicht immer notwendigerweise den Taten und der Wirklichkeit entsprechen. Angesichts der Haltung der Studenten und der Politiker, die in der Sowjetunion gewesen seien, verringere sich der russische Einfluß. Ein anderer Aspekt dieser Frage sei der chinesische Versuch, der Sowjetunion den Rang als größter kommunistischer Macht abzulaufen. Gleichzeitig glaube er persönlich, daß Rotchina versuche, in Afrika Boden zu gewinnen und auf aufrichtige Weise dort Freunde zu bekommen. Dies könnte dazu führen, daß die Chinesen so sehr von den Afrikanern akzeptiert würden, daß sie dann tun könnten, was sie wollten.

Der Herr Minister fragte, welches die Ursachen dafür seien.

Der Botschafter erwiderte, er persönlich habe weder mit Russen noch mit Chinesen einen Kontakt gehabt, er halte es aber für denkbar, daß die Russen doch Europäer, und zwar Osteuropäer seien, die einen ziemlich hohen Standard hätten. Die Chinesen hätten einen Standard, der dem afrikanischen sehr viel vergleichbarer sei und ihnen damit auch den Zugang erleichtere.

Der Herr Minister bezeichnete dies ebenfalls als denkbar. Er verwies dann darauf, daß es eine Anpassung gebe, die dazu führen könne, daß man mit anderen gut auskomme, daß es aber auch eine andere Anpassung gebe, die sich plötzlich zu sehr viel mehr entwickle und zu einer Art Führungsanspruch führen könnte.

Der Botschafter erklärte, auch hier bewege er sich im Bereich der Spekulation. China sei ein noch größeres Land als die Sowjetunion und halte sich möglicherweise für noch mehr berechtigt, die kommunistische Welt zu führen.

Ministerbüro, Bd. 242 


\section{2}

\section{Gespräch des Bundesministers Schröder mit dem amerikanischen Botschafter McGhee}

Der Herr Bundesminister des Auswärtigen empfing am 17. Mai 1963 um 12.30 Uhr den Botschafter der Vereinigten Staaten von Amerika zu seinem Antrittsbesuch.

Nach der Begrüßung brachte der Herr Minister seine Freude darüber zum Ausdruck, den Botschafter so prompt bei sich zu sehen. Er vermute, daß diesen viel Arbeit erwarte, wofür er ihm alles Gute wünschen möchte.

Der Botschafter bedankte sich für die freundlichen Worte; er freue sich, daß er seinerseits so bald empfangen wurde, und sehe den ihn erwartenden Aufgaben mit Spannung und Freude entgegen.

Der Herr Minister sagte, er habe viel von dem gelesen, was der Botschafter in der letzten Zeit erklärt habe ${ }^{2}$, und habe daraus den Eindruck gewonnen, daß dieser bereits sehr gute Einsicht in die deutschen Probleme habe.

Der Botschafter sei vor seiner Abreise noch bei Herrn Minister Rusk gewesen, der mit großer Achtung von dem Herrn Minister gesprochen habe und ihm herzliche Grüße an ihn aufgetragen habe.

Der Herr Minister gab seiner Freude Ausdruck, daß ein Mann Botschafter wurde, der Rusk schon seit seiner Studentenzeit eng verbunden sei $^{3}$, denn jede Arbeit werde viel angenehmer, wenn sie auf persönlicher Sympathie beruhe. Er hätte geglaubt, Herrn Minister Rusk noch vor seiner Reise nach Ottawa treffen zu können, aber seine für diese Woche geplante Reise nach Washington $^{5}$ sei verschoben worden. Gestern sei der deutsch-französische Vertrag im Bundestag ratifiziert worden ${ }^{6}$, und angesichts der Bedeutung der Angelegenheit sei er hiergeblieben. Hätte die Ratifizierung nächste Woche stattgefunden, so wäre er diese Woche nach Washington geflogen. Außerdem sei ja dort diese Woche ein Kollege von ihm zu Gast ${ }^{7}$, und eine Häufung von Besuchen hätte er vermeiden wollen.

1 Die Gesprächsaufzeichnung wurde von der Dolmetscherin Thoenes am 17. Mai 1963 gefertigt. Hat Bundesminister Schröder am 18. Mai 1963 vorgelegen.

2 Botschafter McGhee äußerte sich unter anderem in einem Interview mit der Deutschen Presseagentur zu den deutsch-amerikanischen Beziehungen, der Rolle der Bundesrepublik in der EWG sowie der Präsenz amerikanischer Truppen in Berlin (West). Vgl. dazu Süddeutsche ZEITUNG, Nr. 106 vom 3. Mai 1963, S. 4.

3 Zur Bekanntschaft mit Außenminister Rusk vgl. McGheE, Botschafter, S. 19.

4 Die Konferenz des NATO-Ministerrats fand vom 22. bis 24. Mai 1963 in Ottawa statt. Vgl. dazu Dok. 190.

5 Vgl. dazu Dok. 145, besonders Anm. 19.

6 Zur Ratifizierung des deutsch-französischen Vertrags vgl. Dok. 170, Anm. 27.

7 Bundesminister Krone hielt sich vom 9. bis 17. Mai 1963 in den USA auf. 
Der Botschafter sagte, daß man sich sehr gefreut hätte, den Herrn Minister außerdem in Washington begrüßen zu können.

Der Herr Minister fuhr fort, daß er sich auf ein Wiedersehen mit Herrn Minister Rusk in Ottawa freue und ihm wohl am Dienstagabend u. a. über die Ankunft des Botschafters berichten könne.

Der Botschafter sagte noch einmal, wie sehr sich Amerika gefreut habe, Herrn Krone als Gast bei sich zu sehen.

Der Herr Minister meinte, daß man später, nach dem Besuch Präsident Kennedys Ende nächsten Monats ${ }^{8}$, Gelegenheit haben werde, über eine Reihe von Dingen ausführlich zu diskutieren. Es sei gut, von Zeit zu Zeit nach Washington zu kommen, um die ganze Atmosphäre einzufangen und verschiedene wichtige Persönlichkeiten zu treffen. Er sei das letzte Mal im November zusammen mit dem Herrn Bundeskanzler dort gewesen ${ }^{9}$, und seither wäre ja einige Zeit vergangen. Nach dem Besuch des Präsidenten könne man vielleicht einen Termin im Frühherbst ins Auge fassen ${ }^{10}$ und nach gründlichen Vorbereitungen ausführlich über einige Angelegenheiten beraten. Im Herbst sei auBerdem in Deutschland ein Kanzlerwechsel zu erwarten ${ }^{11}$, wodurch die deutsche Politik wohl etwas in Bewegung geraten werde.

Der Botschafter gab seiner Hoffnung Ausdruck, daß die Vorbereitungen für den Besuch des Präsidenten ohne Schwierigkeiten verliefen, und fragte, ob es für die deutschen Stellen noch Probleme gäbe.

Der Herr Minister schnitt eine Frage an, über die man gestern im Kabinett beraten habe, ob nämlich der Präsident vor dem Bundestag sprechen ${ }^{12}$ solle. Die Meinungen gingen etwas auseinander; er persönlich hielte es für eine gute Idee, obwohl es in der Vergangenheit nicht üblich gewesen sei. Ausnahmen wären der Speaker Joe Martin und der Präsident des dänischen Parlamentes, Federspiel, in seiner Eigenschaft als Präsident der europäischen Versammlung in Straßburg gewesen. Außerdem habe der Bundestag an dem in Frage kommenden Montag keine normale Sitzung anberaumt, das ließe sich jedoch machen. Er persönlich sei für eine kurze Rede als Eröffnung einer guten Tradition, ohne daß der Bundestag gezwungen wäre, jedem Besucher, sei es Staats- oder Regierungschef, die gleiche Möglichkeit einzuräumen. Zweitens habe man daran gedacht, einen Teil des Bundestags nach Frankfurt einzuladen, wo der Präsident des Bundestags ${ }^{13}$ den Vorsitz in der Paulskirche übernehmen solle. Aus historischen Gründen (Paulskirche als Sitz einer früheren

8 Präsident Kennedy besuchte vom 23. bis 26. Juni 1963 die Bundesrepublik. Vgl. dazu Dok. 206208.

9 Zum Besuch des Bundeskanzlers Adenauer und des Bundesministers Schröder vom 13. bis 16. November 1962 in den USA vgl. Dok. 37, Anm. 26.

10 Bundesminister Schröder besuchte vom 19. bis 27. September 1963 die USA. Vgl. dazu Dok. 348, Dok. 349, Dok. 353, Dok. 358, Dok. 361, Dok. 362 und Dok. 366-368.

11 Am 23. April 1963 nominierte die CDU/CSU-Fraktion Ludwig Erhard zum Kanzlerkandidaten. Vgl. dazu Osterheld, Kanzlerjahre, S. 210-214.

12 Eine solche Rede wurde während des Besuchs des Präsidenten Kennedy nicht gehalten.

13 Eugen Gerstenmaier. 
Nationalversammlung) sei das ein interessanter Gedanke, aber er wisse nicht, ob er auch praktisch sei. ${ }^{14}$

Der Botschafter antwortete, er habe von diesem Problem gehört, hielte die Anregung für gut, wolle aber der deutschen Regierung keine Ungelegenheiten bereiten.

Der Herr Minister erwartete keine großen Schwierigkeiten, das Parlament habe lediglich gewisse Befürchtungen hinsichtlich der Zukunft. Er habe den Bundestagspräsidenten noch nicht selbst gesprochen, aber man werde bei deutschen Stellen noch darüber sprechen; der Gedanke sei neu, aber noch nicht endgültig, und nach seiner Rückkehr werde die Angelegenheit geregelt. Mehr als 35-45 Minuten seien ja nicht vonnöten, so daß die Angelegenheit am Montagmorgen eingeschoben werden könne. Weiterhin sei er für eine solche Ansprache, weil dies die leichteste Möglichkeit sei, in Kontakt mit dem ganzen Parlament zu kommen. Die Parlamentarier kämen normalerweise bei einem solchen Besuch immer etwas zu kurz, daher wäre diese Veranstaltung auch gut für ihr Selbstgefühl.

Der Botschafter stimmte diesen Ausführungen zu unter dem Hinweis, daß die Parlamentarier ja sehr wichtig seien, weil man von ihnen das nötige Geld bekäme.

Der Herr Minister erinnerte sich an den Staatsbesuch Präsident Lübkes im vergangenen Herbst und daran, daß dieser zur großen Zufriedenheit beider Seiten im Parlament in Neu Delhi gesprochen habe. ${ }^{15}$

Der Botschafter bot daraufhin an, die Sache, nachdem sie von den deutschen Stellen für gut befunden worden wäre, auch in Amerika noch einmal zur Sprache zu bringen.

Der Herr Minister meinte jedoch, sie würde für den Präsidenten keine zusätzliche Veranstaltung bedeuten, nur eine Veränderung der Szenerie, und ginge wahrscheinlich zu Lasten einer ersten Unterhaltung mit dem Bundeskanzler oder dem Bundespräsidenten. Es sei aber wohl im Sinne des amerikanischen Präsidenten, stets möglichst viele verschiedene Dinge zu unternehmen. Der Herr Minister führte weiter aus, er habe den Bundeskanzler gestern noch nicht selbst gesehen, er selbst sei aber schon früher von den Vorteilen einer Ansprache im Parlament überzeugt gewesen als der Bundeskanzler, der befürchtete, daß sich für den Präsidenten Schwierigkeiten hinsichtlich der politischen Thematik ergäben.

Der Botschafter schloß sich den Ausführungen insofern an, daß der Präsident vor dieser Schwierigkeit wohl jedesmal stehe, wo er auch spreche. Dann fragte er den Herrn Minister, was dieser sich von Ottawa verspräche.

Der Herr Minister erwartete, daß man in der IANF-Sache ${ }^{16}$ zu einem Ergebnis

14 Präsident Kennedy sprach am 25. Juni 1963 in der Paulskirche in Frankfurt/Main. Für den Wortlaut vgl. Public Papers, Kennedy 1963, S. 516-521.

15 Bundespräsident Lübke hielt sich vom 26. November bis 4 . Dezember 1962 in Indien auf und sprach am 27. November vor beiden Häusern des indischen Parlaments. Für den Wortlaut der Rede vgl. Bulletin 1962, S. 1869-1871.

16 Zur Inter-Allied Nuclear Force vgl. bereits Dok. 158. Vgl. dazu weiter Dok. 190. 
kommen werde, wenn nicht de Gaulle in letzter Minute mit einer neuen Idee aufwartet. Er glaube aber, daß Frankreich seine Zustimmung zu den jetzt ausgearbeiteten Formeln geben werde.

Die MLF-Angelegenheit ${ }^{17}$ werde nicht offiziell zur Diskussion stehen, sondern nur am Rande behandelt werden, jedoch sei die Einstellung der Bundesregierung positiv. In der deutschen Öffentlichkeit, in Pressekommentaren etc. könne man zwar auch andere Stimmen hören, aber im allgemeinen sei man in Deutschland für das Projekt. Er habe nun gerade gelesen, daß die London Times eine volle Breitseite gegen das Projekt losgelassen habe, aber die Zeitung sei nicht immer die Stimme der britischen Regierung, und aus seinem gestrigen Gespräch mit dem britischen Botschafter ${ }^{18}$ habe er den Eindruck gewonnen, daß die britische Regierung dafür sei, von den Kosten abgesehen, aber die Entwicklung in Großbritannien sei noch nicht ganz klar. Frankreichs Haltung sei natürlich ablehnend, die Italiens hänge von seiner zukünftigen Regierung ${ }^{19} \mathrm{ab}$, sie sei jedoch vielleicht positiv ${ }^{20}$, von den Niederlanden und Belgien könne man noch nichts sagen. Entscheidend sei jedoch, daß Großbritannien nicht nur Nassau 6, sondern auch Nassau $8^{21}$ annähme.

Der Botschafter meinte, der Herr Minister sähe die Lage völlig richtig, auch er glaube, daß es auf Großbritannien ankäme. Belgien sei wohl eher dafür, jedenfalls sei die Haltung Spaaks persönlich positiv.

Der Herr Minister wiederholte, auch Italien wäre natürlich willkommen, aber entscheidend wäre Großbritannien, dessen Entscheidung wiederum die anderen Länder beeinflussen würde.

Er sei nun gespannt, welchen Eindruck Europa auf den Botschafter machen werde, wenn er nun richtig auf dem europäischen Kontinent lebe. Er werde die interessante Entwicklung in der EWG verfolgen, die in der Zukunft noch einiges Kopfzerbrechen machen werde.

Der Botschafter sagte, er habe die Rede des Herrn Ministers vom 2. April 1963, die er im Ministerrat in Brüssel gehalten habe ${ }^{22}$, mit außerordentlichem Interesse verfolgt und hielte sie für sehr bedeutsam.

Der Herr Minister fuhr fort, man brauche noch viel Unterstützung in dieser

17 Zum Projekt einer multilateralen Atomstreitmacht vgl. Dok. 120.

Zur Behandlung der MLF auf der Tagung des NATO-Ministerrats vgl. weiter Dok. 190. Vgl. dazu auch den Drahterlaß des Bundesministers Schröder, z. Z. Ottawa, vom 23. Mai 1963; Ministerbüro, VS-Bd. 8489; B 150, Aktenkopien 1963.

18 Frank K. Roberts.

19 Nach den Kammer- und Senatswahlen in Italien am 28./29. April 1963, die zu schweren Stimmverlusten der Christlich-Demokratischen Partei führten, trat das von Ministerpräsident Fanfani geführte Kabinett am 16. Mai 1963 zurück. Die Versuche des Politischen Sekretärs der ChristlichDemokratischen Partei, Moro, mit der Sozialistischen Partei unter Nenni eine Regierung zu bilden, scheiterten am 18. Juni 1963. Am 19. Juni beauftragte Staatspräsident Segni den Präsidenten der Abgeordnetenkammer, Leone, mit der Bildung einer christdemokratischen Minderheitsregierung. Vgl. dazu AdG 1963, S. 10658.

20 Zur grundsätzlich positiven Haltung Italiens zur MLF vgl. den Drahtbericht des Botschafters Klaiber, Rom, vom 3. Mai 1963; Büro Staatssekretär, VS-Bd. 432; B 150, Aktenkopien 1963.

$21 \mathrm{Zu}$ den Paragraphen 6 und 8 des Nassau-Abkommens vom 21. Dezember 1962 vgl. Dok. 12, Anm. 10 und 11.

22 Für den Wortlaut der Rede des Bundesministers Schröder vgl. BulletiN 1963, S. 543-548. 
Sache, und ein großer Teil der Tätigkeit des Botschafters werde der Verstärkung dieser Linie in Verbindung mit anderen gewidmet sein. Europa sei bereits in vollem Schwung gewesen, zur Zeit sei es etwas zurückgefallen ${ }^{23}$, aber man müsse auch berücksichtigen, daß die Probleme schwieriger geworden seien. Die Probleme der EWG, der Genfer Gespräche, der GATT-Verhandlungen $^{24}$ und der Kennedy-Runde ${ }^{25}$ werden uns nicht nur wegen ihres eigenen Gewichtes, sondern auch wegen der Technik in diesem und dem kommenden Jahr vor große Schwierigkeiten stellen.

Der Herr Minister sagte im Laufe des Gesprächs weiter, daß der Botschafter einen Eindruck von der europäischen Landwirtschaft bekommen werde, sowie von der deutschen Landwirtschaft und ihren Problemen und ihrem Zusammenhang mit der Innenpolitik, der ja auch in den USA auf dem entsprechenden Gebiete bestehe.

Der Botschafter bekräftigte dies und betonte die große Bedeutung der landwirtschaftlichen Probleme, die sich auch darin zeigte, daß das Parlament bei der Sitzung, bei der er bestätigt wurde ${ }^{26}$, eigentlich nur vom Geflügelproblem ${ }^{27}$ gesprochen habe.

Der Herr Minister führte noch aus, daß er von der amerikanischen Regierung eine Einladung erhalten habe, anschließend an die Gespräche in Ottawa nach Washington zu kommen, er könne aber dieser Einladung nicht Folge leisten, da er direkt nach Mexiko zu einer Konferenz der lateinamerikanischen Botschafter ${ }^{28}$ reise. Dieses Treffen sei von großer Bedeutung und werde ihn ungefähr eine Woche in Anspruch nehmen. Anschließend käme er zurück und hoffe auf eine gute Gelegenheit, noch vor dem Besuch des Präsidenten mit dem Botschafter zusammenzukommen.

Er gab seiner Hoffnung Ausdruck, die Erwartungen des Botschafters möchten sich erfüllen, und seine Arbeit ihn zufriedenstellen. Er könne ihm ganz offen sagen, daß ihm der Ruf eines erfolgreichen Geschäftsmannes, Politikers und Diplomaten vorausgegangen sei, eine Mischung, die in Deutschland sehr geschätzt werde.

23 Zum gescheiterten Beitritt Großbritanniens zur EWG vgl. Dok. 60.

24 Zur Ministertagung der GATT-Vertragspartner vom 16. bis 21. Mai 1963 vgl. Dok. 164, Anm. 5.

25 Zur Kennedy-Runde vgl. Dok. 115, Anm. 10. Vgl. dazu auch den Vermerk des Staatssekretärs Lahr vom 18. Mai 1963; Büro Staatssekretär, Bd. 405.

26 Die Ernennung von George McGhee zum amerikanischen Botschafter in der Bundesrepublik wurde am 24. April 1963 vom Senat bestätigt. Vgl. dazu Congressional Record, Bd. 109/5, S. 6932.

27 Der „Hähnchen-Krieg“ wurde durch die Verordnung des EWG-Ministerrats vom 20. Juni 1962 über die „Festsetzung des Einschleusungspreises für geschlachtete Enten, Puten, Gänse, Perlhühner und Legehühner" ausgelöst, nach der die Abgaben auf eingeführtes Geflügel erhöht wurden. Die Abgabenerhöhung betraf vor allem die amerikanischen Geflügelzüchter. Vgl. dazu AMTSBLATT DER EuRopäISChEN GEMEINSChafTEn 1962, S. $1557 \mathrm{f}$.

Der Konflikt zwischen den USA und der EWG verschärfte sich, als die EWG-Landwirtschaftsminister am 30. Mai 1963 beschlossen, die Einfuhrabgaben für Geflügel aus den USA nicht - wie von der EWG-Kommission vorgeschlagen - zu senken, sondern zu erhöhen. Zum „HähnchenKrieg" vgl. weiter Dok. 346.

28 Zur Botschafterkonferenz in Guernavaca vom 25. bis 31. Mai 1963 vgl. die Aufzeichnung des Referats I B 2 vom 5. Juni 1963; Büro Staatssekretär, VS-Bd. 391; B 150, Aktenkopien 1963. Vgl. dazu weiter Dok. 195. 
Mit den Dankesworten des Botschafters für den freundlichen Empfang und gegenseitigen Wünschen für die Zukunft nahm das Gespräch um 12.15 Uhr ${ }^{29}$ ein Ende.

Ministerbüro, Bd. 242

173

\section{Ministerialdirektor Jansen an die Botschaft in Kairo}

I B 4-84.00/90.35-1072/63 VS-vertraulich

Fernschreiben Nr. 257
18. Mai $1963^{1}$

Aufgabe: 22. Mai 1963, 16.30 Uhr

1) Zur dortigen streng vertraulichen Unterrichtung wird mitgeteilt, daß das Kabinett sich wiederholt mit der Frage der deutschen Experten in der VAR ${ }^{2}$ befaßt hat. Die Bundesregierung teilt die Ansicht ihrer westlichen Allierten, vor allem der Vereinigten Staaten, nach welcher der Abzug der deutschen Raketensachverständigen die Abhängigkeit der VAR vom Ostblock verstärken würde, ohne das ägyptische Raketenbauprogramm entscheidend zu treffen. ${ }^{3}$ Trotzdem sieht sich die Bundesregierung nicht in der Lage, die Arbeit der Deutschen zu billigen oder zu unterstützen. Sie beabsichtigt jedoch nicht, gesetzliche Maßnahmen gegen die deutschen Wissenschaftler ihrerseits vorzubereiten, setzt vielmehr die Suche nach anderen Lösungsmöglichkeiten fort. ${ }^{4}$

Die Bemühungen einer Gruppe von Abgeordneten um einen Gesetzentwurf sind unbeeinflußt von dieser Einstellung geblieben. Es ist aber noch nicht ab-

29 Die Zeitangabe wurde von Bundesminister Schröder hervorgehoben. Dazu handschriftliche Randbemerkung: „Wenn es erst 12.30 begonnen hat?“

1 Der Drahterlaß wurde Staatssekretär Carstens am 17. Mai 1963 mit einem begleitenden Vermerk des Ministerialdirektors Jansen übermittelt.

Hat dem Leiter des Referats „Naher Osten und Nordafrika“, Schirmer, am 20. Mai und Carstens am 21. Mai 1963 vorgelegen.

2 Vgl. dazu besonders Dok. 157.

3 Mit Drahtbericht vom 17. April 1963 schilderte Botschafter Knappstein, Washington, die amerikanische Haltung: „Nach Ansicht der amerikanischen Regierung liegt die Tätigkeit deutscher Experten in der VAR im Interesse des Westens, soweit sie auf dem Gebiet der Luftfahrt tätig sind und sich dabei keines klassifizierten Materials bedienen." Vgl. Abteilung I (I B 4), VS-Bd. 221; B 150, Aktenkopien 1963.

Vgl. dazu auch Referat I B 4, Bd. 48.

4 Das Bundeskabinett befaßte sich am 27. März, 8. April, 24. April und 2. Mai 1963 mit der Thematik. In der letztgenannten Sitzung entschied es sich auf Vorschlag des Bundeskanzlers Adenauer dafür, daß in der Behandlung der Angelegenheit zunächst „kurz getreten werden solle“. Vgl. dazu den Vermerk des Vortragenden Legationsrats I. Klasse Schirmer vom 2. Mai 1963; Referat I B 4, Bd. 17. 
zusehen, wie weit der inzwischen weitgehend fertiggestellte Entwurf im Parlament angenommen werden wird. ${ }^{5}$

2) Im Hinblick auf die heftige Pressepolemik im Zusammenhang mit den deutschen Raketenexperten werden Sie gebeten, in vorsichtiger Weise mit den drei Herren einzeln oder gemeinsam Fühlung aufzunehmen. Ein informelles Gespräch, das zweckmäßigerweise durch den Botschaftsrat zu führen wäre, könnte an das Schreiben anknüpfen, das die Herren an den Herrn Bundeskanzler $^{6}$ gerichtet haben. Das Schreiben ist dem Herrn Bundeskanzler vorgelegt worden.

Ziel der Fühlungnahme sollte sein, einer persönlichen Verbitterung die Spitze abzubrechen und den Herren die vielschichtigen außen- und innenpolitischen Probleme zu erklären, die mit ihrer Tätigkeit indirekt verbunden sind. Das Verhalten der Bundesregierung gegenüber den jüngsten israelischen Presseangriffen wurde von dem Bestreben geleitet, einerseits das seit Jahren planmäßig unternommene Werk einer Aussöhnung und Annäherung zwischen dem deutschen und dem jüdischen Volk nicht zu gefährden und andererseits auch das gute deutsch-arabische Verhältnis nicht zu belasten. Angesichts des wachsenden militärischen und politischen Potentials des arabischen Nationalismus ist die heftige Reaktion Israels auf die zum Teil übertriebenen Meldungen über die Tätigkeit der deutschen Wissenschaftler psychologisch erklärlich. Sie hat zu einer schweren Erschütterung der sich ohnehin nur langsam entwickelnden Bereitschaft des Judentums geführt, sich mit dem deutschen Volk auszusöhnen. Unabhängig davon werden die Anschläge ${ }^{7}$ des israelischen Geheimdienstes auf die deutschen Wissenschaftler von der Bundesregierung verurteilt. Durch die Entlassung des Chefs des Geheimdienstes ${ }^{8}$ ist auch die israelische Regierung von diesen Praktiken abgerückt.

Wir sind ${ }^{9}$ bereit zu unterstellen, daß die deutschen Herren ihre Tätigkeit in Ägypten weder aus rassischen noch aus falsch verstandenen nationalistischen Motiven angetreten haben, sondern die ägyptischen Vertragsangebote aus wissenschaftlichen oder finanziellen Gründen annahmen. Auch haben wir wiederholt erklärt, daß nichts auf eine Mitwirkung Deutscher an der Herstel-

5 Die Initiative für einen Gesetzentwurf, der es ermöglichen sollte, die Beteiligung Deutscher an der Herstellung von Waffen außerhalb des Bundesgebiets zu unterbinden, ging insbesondere vom CDU-Abgeordneten Böhm aus. Am 28. Juni 1963 verabschiedete der Bundestag einen von allen drei Fraktionen eingebrachten Antrag, in dem die Bundesregierung aufgefordert wurde, entsprechende gesetzgeberische Maßnahmen einzuleiten. Vgl. dazu BT ANLAGEN, Bd. 85, Drucksache IV/ 1388 neu. Vgl. auch VoGEL, Dialog I/1, S. 234-237.

6 Drei in leitender Position in der VAR tätige deutsche Wissenschaftler, Görcke, Pilz und Klein wächter, wandten sich in Schreiben vom 6. bzw. 7. April 1963 an Bundeskanzler Adenauer, um die gegen sie und ihr Projekt erhobenen Vorwürfe zurückzuweisen. Für die Schreiben vgl. Referat I B 4, Bd. 18.

7 Dieses Wort wurde von Ministerialdirektor Jansen handschriftlich eingefügt. Dafür wurde gestri. chen: „Handlungen“.

8 Zum Rücktritt von Iser Halprin am 1. April 1963 vgl. Frankfurter Allgemeine Zeitung, Nr. 78 vom 2. April 1963, S. 4; Der Spiegel, Nr. 19 vom 8. Mai 1963, S. 71.

9 Die beiden letzten Worte wurden von Staatssekretär Carstens handschriftlich eingefügt. Dafür wurde gestrichen: „Die Bundesregierung ist“. Entsprechend wurden zwei weitere Stellen in diesem Absatz umformuliert. 
lung von $\mathrm{ABC}-$ Waffen schließen läßt. ${ }^{10}$ Wir können auf der anderen Seite nicht darüber hinwegsehen, daß dem ägyptischen Raketenprogramm keineswegs ausschließlich zivile Bedeutung zuzumessen ist. ${ }^{11}$

Es wird gebeten, über den Verlauf der Unterredungen ausführlich zu berichten. ${ }^{12}$

3) $\mathrm{Es}^{13}$ wird weiter gebeten, für den ${ }^{14}$ Dienstgebrauch einen sachlichen zusammenfassenden Bericht über den gegenwärtigen Stand des VAR-Raketenbauprogramms, seine Bedeutung für den militärischen und zivilen Sektor sowie die Rolle, die die deutschen Fachleute hierbei spielen, abzugeben. ${ }^{15}$

Jansen $^{16}$

Abteilung I (I B 4), VS-Bd. 221

10 Vgl. dazu Dok. 133, Anm. 21.

11 Auf Weisung des Staatssekretärs Carstens wurde von Ministerialdirektor Jansen an dieser Stelle gestrichen: „Die Bundesregierung bedauert es grundsätzlich, daß bisher in der Bundesrepublik keine ausreichende Möglichkeit bestand, um allen wertvollen wissenschaftlichen Kräften angemessene Arbeitsmöglichkeiten zu bieten. Sie wird ihre Bemühungen fortsetzen, diesem Mangel abzuhelfen."

12 Mit Drahtbericht vom 27. Mai 1963 legte Botschafter Weber, Kairo, dar, warum er mit den deutschen Experten noch nicht in Verbindung getreten sei: „Ich betrachte die Angelegenheit hier als so heikel, daß das Bekanntwerden auch nur der unauffälligsten amtlichen Kontaktaufnahme mit den in Frage kommenden Herren unabsehbare Folgen für unsere Beziehungen haben könnte, und ich muß leider davon ausgehen, daß selbst noch so vorsichtige Schritte der Botschaft nicht geheimgehalten werden können." Mit Blick auf den bevorstehenden Besuch des ägyptischen Vizepräsidenten Amer in der UdSSR wies er auf die Gefahr verstärkter ägyptisch-sowjetischer Kontakte hin. Er sicherte jedoch zu, sich um eine unauffällige Kontaktaufnahme im Rahmen eines gesellschaftlichen Anlasses zu bemühen. Vgl. Abteilung I (I B 4), VS-Bd. 221; B 150, Aktenkopien 1963.

13 Dieses Wort wurde von Ministerialdirektor Jansen handschriftlich eingefügt. Dafür wurde gestrichen: „Um weiteren Angriffen und Verdächtigungen entgegentreten zu können,“.

14 An dieser Stelle wurde von Ministerialdirektor Jansen gestrichen: „internen“.

15 Am 14. Juni 1963 legte die Botschaft in Kairo den angeforderten Bericht vor. Vgl. Abteilung I (I B 4), VS-Bd. 221. Vgl. zur Thematik weiter Dok. 189.

16 Paraphe vom 21. Mai 1963. 


\section{Gespräch des Staatssekretärs Carstens mit dem sowjetischen Botschafter Smirnow}

Aufzeichnung über ein Gespräch zwischen Staatssekretär Professor Carstens und dem sowjetischen Botschafter Smirnow am 20. Mai 1963, $11.00 \mathrm{Uhr}$, im Büro des Herrn Staatssekretärs.

Staatssekretär Carstens sagte, er habe den Botschafter zu sich gebeten, um eine Reihe von Punkten mit ihm zu besprechen, die alle in den humanitären Bereich fielen, denn sie beträfen Menschen, um deren Schicksal sich die Bundesregierung bekümmern müsse.

Der erste Punkt betreffe die Rückführung von Deutschen aus der Sowjetunion. Wie der Botschafter ja wisse, sei am 25. 4. 1958 zwischen den beiden Regierungen eine Vereinbarung über die Rückführung von Personen deutscher Volkszugehörigkeit, die früher die deutsche Staatsangehörigkeit besessen hätten, geschlossen worden. ${ }^{2}$ Inzwischen sei es zu Meinungsverschiedenheiten darüber gekommen, ob diese Aktion befristet sei oder nicht. Die Bundesregierung sei der Ansicht, das in der Vereinbarung genannte Datum 31.12.1959 bedeute keine Ausschlußfrist ${ }^{3}$, und beziehe sich dabei auf die Äußerung des stellvertretenden sowjetischen Außenministers Semjonow gegenüber dem damaligen Botschafter Lahr und auf das Schreiben des sowjetischen Ministerpräsidenten Chruschtschow vom 13.2.1961 an den Herrn Bundeskanzler, worin dieser versichere, die Sowjetunion habe nicht die Absicht, Personen deutscher Volkszugehörigkeit, die früher die deutsche Staatsangehörigkeit besessen hätten, gegen ihren Willen in der Sowjetunion zurückzubehalten. ${ }^{4}$

Die Bundesregierung sei der Ansicht, daß noch rund 10000 derartige Personen in der Sowjetunion lebten, die den Wunsch hätten, in die Bundesrepublik auszureisen. Er, der Staatssekretär, werde dem Botschafter anschließend eine Note überreichen, in der der deutsche Standpunkt dargelegt sei. ${ }^{5}$ Darin werde auch auf die Vorgeschichte und die beiderseitigen Erklärungen zu dieser Frage ausführlich eingegangen. Die Bundesregierung würde es begrüßen,

1 Die Gesprächsaufzeichnung wurde von Dolmetscher Richter am 21. Mai 1963 gefertigt. Vgl. dazu auch den Drahtbericht des Staatssekretärs Carstens vom 20. Mai 1963 an Bundesminister Schröder, z. Z. Ottawa; Büro Staatssekretär, VS-Bd. 442; B 150, Aktenkopien 1963.

2 Die Vereinbarung über die Repatriierung von Personen deutscher Volkszugehörigkeit erfolgte bereits am 8. April 1958 durch in Moskau abgegebene mündliche Erklärungen. Sie war von deutscher Seite zur Bedingung für den Abschluß eines Wirtschafts- und Konsularabkommens mit der UdSSR gemacht worden, das am 25. April 1958 in Bonn unterzeichnet wurde. Für den Wortlaut der Erklärung vom 8. April 1958 vgl. Bulletin 1958, S. 630.

3 Dazu die sowjetische Erklärung vom 8. April 1958: „Die sowjetische Seite geht davon aus, daß die mit der getroffenen Vereinbarung zusammenhängenden Maßnahmen bis Ende 1959 durchgeführt sein werden." Vgl. BuLLETIN 1958, S. 630.

4 Für den Wortlaut dieses Schreibens vgl. Bulletin 1961, S. $445 \mathrm{f}$.

5 Für den Wortlaut der Note vom 20. Mai 1963 vgl. Bulletin 1963, S. 789 f. 
wenn zwischen der sowjetischen Regierung und der Bundesregierung Gespräche über die Rückführung der noch in der Sowjetunion verbliebenen Deutschen geführt werden könnten, und glaube, daß eine Förderung dieser Angelegenheit den Beziehungen zwischen beiden Ländern zugute käme.

Botschafter Smirnow erwiderte, er werde die Note sicherlich lesen, könne aber schon im voraus sagen, daß die Bundesregierung damit ein Problem aufwerfe, das längst keines mehr sei. Die Frage der Rückführung sei endgültig gelöst. Alle in Frage kommenden Personen seien repatriiert worden, darunter auch solche wie Herr Foertsch, der jetzige Generalinspekteur der Bundeswehr 6 . Dies sei sowohl im Wege der Heimsendung großer Gruppen als auch im Wege der Ausreise von Einzelpersonen geschehen, die den Wunsch geäußert hätten, in die Bundesrepublik überzusiedeln. Nun aber nenne der Herr Staatssekretär wieder große Zahlen, wie zehntausend Deutsche, die dort angeblich auf ihre Repatriierung warteten. Er wundere sich, daß man von deutscher Seite nicht gleich die mehr als eine Million Menschen deutscher Volkszugehörigkeit beanspruche, die die sowjetische Bevölkerungsstatistik in der Sowjetunion ausweise. Er wiederhole: Alle ausreisewilligen Deutschen seien längst ausgereist. Daneben gebe es selbstverständlich viele Deutsche sowjetischer Staatsangehörigkeit, die in der Sowjetunion bleiben wollten, so wie es auch in der Bundesrepublik etwa 80000 ehemalige sowjetische Staatsangehörige aus den baltischen Ländern, der Ukraine usw. gebe, die in ihrer Gesamtheit nicht zurückkehren wollten. Wo dies in einzelnen Fällen anders sei, erfolge eine Rückführung in beiden Richtungen auf dem dafür vorgesehenen gesetzlichen Wege. Die Verhandlungen, die der Herr Staatssekretär über diesen Gegenstand vorschlage, seien deshalb unnötig.

Staatssekretär Carstens entgegnete, man müsse unterscheiden zwischen den Kriegsgefangenen und anderen Personen. Die deutschen Kriegsgefangenen in der Sowjetunion seien alle nach Hause zurückgekehrt, wofür die Bundesregierung ihren Dank öffentlich ausgesprochen habe. Die Bundesregierung sei auch gewissen von bestimmten Gruppen in Deutschland in die Welt gesetzten Gerüchten entgegengetreten, als halte die Sowjetunion noch deutsche Kriegsgefangene in sogenannten Schweigelagern zurück.

Botschafter Smirnow unterbrach hier die Argumentation des Herrn Staatssekretärs und nahm unmittelbar Bezug auf die Frage der früheren Staatsangehörigkeit von Personen deutscher Volkszugehörigkeit in den während des Krieges von Deutschland besetzten Gebieten. Er sagte, er selbst habe gleich nach dem Kriege viele solche Deutsche gesprochen. Diese hätten einhellig erklärt, sie seien in den Jahren nach 1939 von den deutschen Besatzern durch Androhung von Gewalt zur Annahme der deutschen Staatsangehörigkeit gezwungen worden und hätten deshalb sofort nach der Rückeroberung durch die Rote Armee den sowjetischen Behörden ihren Willen zum Ausdruck gebracht, wieder als sowjetische Staatsangehörige anerkannt zu werden. ${ }^{7}$

6 Friedrich Foertsch wurde im Frühjahr 1942 als Oberst der Wehrmacht an den Nordabschnitt der Ostfront versetzt. Ab 1943 war er Chef des Generalstabes der Heeresgruppe Kurland. 1945 geriet er in sowjetische Kriegsgefangenschaft, aus der er 1955 entlassen wurde. Von April 1961 bis Dezember 1963 war er Generalinspekteur der Bundeswehr.

7 Ein Teil der in der Ukraine angesiedelten Rußlanddeutschen wurde nach dem Einmarsch deut- 
Staatssekretär Carstens erwiderte, die Bundesregierung sei keinesfalls gesonnen, aus solchen Vorfällen irgendwelche Ansprüche abzuleiten. Die Bundesregierung behaupte weiter nichts, als daß ein Teil derjenigen Personen deutscher Volkszugehörigkeit in der Sowjetunion, die früher die deutsche Staatsangehörigkeit besessen hätten ${ }^{8}$, in die Bundesrepublik auszureisen wünsche. Die Bundesregierung behaupte dies auch nicht aufgrund irgendwelcher Vermutungen, sondern besitze darüber unter Mitwirkung des Roten Kreuzes beigebrachte konkrete Unterlagen, die sie der sowjetischen Regierung gerne zur Verfügung stellen würde. Diese Personen fielen nach Ansicht der Bundesregierung unter das Abkommen, und deshalb wünsche die Bundesregierung ein Gespräch mit der sowjetischen Regierung über ihre Rückführung.

Botschafter Smirnow entgegnete, das Rückführungsproblem sei endgültig gelöst und Verhandlungen über ein gelöstes Problem könne es nicht geben. Aus langer persönlicher Erfahrung wisse er im übrigen, daß, wenn die Bundesregierung das Thema Repatriierung aufwerfe, dahinter stets die Absicht stehe, die Beziehungen zur Sowjetunion zu verschlechtern. In der Vermutung, daß das auch diesmal so sei, werde er bestärkt durch das Zusammenfallen dieser Aktion mit dem kürzlich verhängten Röhrenembargo ${ }^{9}$. Anstatt also, wie sie in ihren Noten versichere, die Beziehungen zur Sowjetunion Schritt um Schritt zu verbessern, tue die Bundesregierung einen Schritt nach dem anderen, um sie zu verschlechtern.

Staatssekretär Carstens erwiderte, er habe doch ausdrücklich gesagt, daß die Bundesregierung eine Lösung der Repatriierungsfrage deshalb wünsche, weil sie sich davon eine Verbesserung der Beziehungen zur Sowjetunion verspreche. Der Botschafter vergesse, daß es sich hier um einen Punkt handele, der die deutsche Öffentlichkeit lebhaft beschäftige. Man habe auf deutscher Seite geglaubt, daß sich die sowjetische Regierung in dieser Frage flexibler verhalten werde. Wenn auch, wie der Botschafter sage, die sowjetische Regierung der Ansicht sei, ein Repatriierungsproblem gebe es nicht, so sei doch die Bundesregierung der gegenteiligen Ansicht, und dies sei nach internationalem Brauch ein ausreichender Anlaß, um Gespräche beider Seiten über diesen strittigen Punkt einzuleiten. Wenn die sowjetische Seite derartige Gespräche ablehne, so bliebe der Bundesregierung nichts anderes übrig, als der sowjetischen Regierung die vollständigen Listen mit den Namen aller zehntausend Heimkehrwilligen zu überreichen. Er frage sich, ob das besser sei.

\footnotetext{
Fortsetzung Fußnote von Seite 566

scher Truppen 1941 in den „Warthegau“ umgesiedelt. Nach dem Einmarsch der Roten Armee in Polen wurden sie als ehemals sowjetische Staatsbürger ebenso wieder in die UdSSR verbracht wie ein Großteil derjenigen Rußlanddeutschen, die mittlerweile in den westlichen Besatzungszonen Deutschlands lebten.

8 Es handelt sich in erster Linie um Deutsche in dem laut Kommuniqué vom 2. August 1945 über die Konferenz von Potsdam (Potsdamer Abkommen) unter sowjetische Verwaltung gestellten Teil Ostpreußens und im Memelland, ferner um die Reichsdeutschen und „Vertragsumsiedler“ der Jahre 1939 bis 1941 aus dem Baltikum und Bessarabien, die nach 1945 aus polnischem bzw. dem polnischer Verwaltung unterstellten Territorium in die UdSSR verbracht wurden.

9 Zum Beschluß des Ständigen NATO-Rats vom 21. November 1962 vgl. Dok. 9, Anm. 5. Vgl. dazu auch bereits Dok. 148 .
} 
Botschafter Smirnow meinte, die sowjetische Seite wisse besser über die Wünsche ihrer Staatsangehörigen Bescheid.

Staatssekretär Carstens entgegnete, die Sowjetunion sei groß. Der Botschafter habe selbst gesagt, daß dort mehr als eine Million Personen deutscher Volkszugehörigkeit lebten.

Es sei also doch nicht merkwürdig, wenn 10000, also etwa 1 Prozent, die Absicht hätten, in die Bundesrepublik auszureisen. Er sei bereit, auf eine positivere Äußerung des Botschafters zu dem Vorbringen der Bundesregierung zu warten.

Botschafter Smirnow wiederholte, er halte es für ein schlechtes Zeichen, daß die Bundesregierung die Repatriierungsfrage erneut aufwerfe. Der sowjetische Standpunkt sei bekannt. Man habe keine Zeit, um über gelöste Probleme zu verhandeln. Ein Repatriierungsproblem existiere für die sowjetische Regierung nicht mehr. Wenn einzelne Personen ausreisen wollten, so könnten sie dies auch jetzt noch beantragen, da ihnen dieses Recht in der Verfassung garantiert sei.

Staatssekretär Carstens sagte dagegen, es handele sich auch gar nicht um Gruppen, sondern durchaus um Einzelpersonen, aber eben um sehr viele.

Botschafter Smirnow sagte, er wisse wohl, daß der erste deutsche Nachkriegsbotschafter in Moskau, Haas, seinerzeit viel Lärm um die große Kartothek von angeblich Heimkehrwilligen in den Kellern der Botschaft gemacht habe. Unter Botschafter Kroll sei davon niemals die Rede gewesen. Aber der neue Botschafter Groepper habe anscheinend die Absicht, in die Haasschen Fußstapfen zu treten. Dies sei nicht nur merkwürdig, sondern es sei sehr ernst, wenn eine längst erledigte Frage immer wieder aufgewärmt werde.

Staatssekretär Carstens erwiderte, der Unterschied sei eben der, daß die sowjetische Regierung das Problem als gelöst betrachte, die Bundesregierung aber nicht. Außerdem müsse er es zurückweisen, daß der Botschafter unsachliche Folgerungen aus dem angeblichen Verhalten der drei Nachkriegsbotschafter in Moskau ziehe. Zum Beispiel habe der Briefwechsel zwischen Bundeskanzler Adenauer und Ministerpräsident Chruschtschow über die Repatriierungsfrage währen der Amtszeit Botschafter Krolls stattgefunden. ${ }^{10}$

Botschafter Smirnow wiederholte, wer aus der Sowjetunion habe ausreisen wollen, habe dies tun können. Wer jetzt diese Absicht habe, könne dies auch heute noch tun. Die Frage sei damit erledigt.

Staatssekretär Carstens sagte, er bedauere diese Haltung des Botschafters sehr und werde sich gezwungen sehen, in nächster Zeit auf diese Frage zurückzukommen und dem Botschafter detailliertes Material zu überreichen.

Staatssekretär Carstens fuhr dann fort, der zweite Punkt, den er mit dem Botschafter besprechen wolle, betreffe ein Konto der Deutschen Botschaft bei der sowjetischen Staatsbank über 574000 neue Rubel, die sich aus Geldern zusammensetzten, die der Deutschen Botschaft von Repatriierten in Verwahrung ge-

10 Für den Wortlaut der Schreiben des Bundeskanzlers vom 18. Oktober 1960 und vom 24. April 1961 an den sowjetischen Ministerpräsidenten sowie des Schreibens von Chruschtschow vom 13. Februar 1961 an Adenauer vgl. DzD IV/5, S. 428 f., sowie DzD IV/6, S. 313 f. und S. 641 f. 
geben worden seien. Er wiederhole hiermit die Bitte, die der sowjetischen Regierung schon mehrfach von der Deutschen Botschaft in Moskau vorgetragen worden sei, nämlich, dieses Konto freizugeben, damit die Gelder den berechtigten Personen ausgezahlt werden könnten. Sicher habe der Botschafter von dieser Frage gehört.

Botschafter Smirnow sagte, er sei ganz allgemein mit diesem Problem vertraut und könne dazu folgendes sagen: Soweit es sich um das normale Konto der Botschaft bei der Staatsbank handele, das aus für die Botschaft dort eingezahlten D-Mark stamme, so könne die Botschaft darüber frei verfügen, so wie er, der sowjetische Botschafter, hier in der Bundesrepublik über die für ihn nach Deutschland überwiesenen Rubel verfügen könne. Bei jenem anderen Konto aber handele es sich um ein ursprüngliches Rubel-Konto, nicht um konvertierte D-Mark, und dafür gälten in der Sowjetunion andere gesetzliche Bestimmungen.

Staatssekretär Carstens erwiderte, in Artikel 19 Ziffer 8 des deutsch-sowjetischen Konsularvertrages sei ausdrücklich vorgesehen, daß der Deutsche Konsul Gelder von deutschen Staatsangehörigen in Verwahrung nehmen könne. ${ }^{11}$ Das aber schließe logisch ein, daß er auch das Recht haben müsse, diese Gelder an die Berechtigten herauszugeben.

Botschafter Smirnow sagte, der Deutschen Botschaft in Moskau sei seinerzeit eine eindeutige Antwort auf ihre Anfrage dieserhalb erteilt worden.

Staatssekretär Carstens sagte, diese Antwort werde von der Bundesrepublik aus dem vorgenannten Grunde nicht als befriedigend angesehen.

Botschafter Smirnow machte längere Ausführungen über die sowjetischen gesetzlichen Bestimmungen, die nicht nur den Transfer von Rubeln auf bestimmte Fälle beschränkten, sondern auch die Ausfuhr von Kunstgegenständen und Altertümern verböten. Was die von den deutschen Repatrianten eingezahlten Gelder angehe, so wisse die sowjetische Regierung nicht, ob diese legal erworben worden seien.

Staatssekretär Carstens machte darauf aufmerksam, daß bei 14000 Repatrianten von den 570000 Rubeln auf den Einzelnen kein sehr großer Betrag entfiele. Auch sei der Betrag absolut gesehen nicht so hoch, daß seine Freigabe ein Problem darstellen könnte.

Botschafter Smirnow meinte, die betreffenden Gelder lägen ja auf dem Konto ganz gut und auch dem Konsularvertrag sei insofern Genüge geschehen, als die sowjetische Regierung keine Einwendungen dagegen erhoben habe, daß sie von der Botschaft in Verwahrung genommen worden seien. Vielleicht werde eines Tages, wenn eine Regelung der großen materiellen Forderungen, die die Sowjetunion an die Bundesrepublik zu stellen habe, in Aussicht stehe, auch über die Freigabe dieses gewiß nicht hohen Betrages gesprochen werden können.

11 Artikel 19, Ziffer 8 des Konsularvertrags mit der UdSSR vom 25. April 1958: „Der Konsul ist befugt ... Urkunden, Geld, Wertgegenstände und sonstige Vermögensgegenstände von Staatsangehörigen des Entsendestaates ... zu verwahren oder für diese in Verwahrung zu nehmen." Vgl. Bundesgesetzblatt 1959, Teil II, S. 238. 
Staatssekretär Carstens verwahrte sich dagegen, zwei so völlig verschiedene Fragen miteinander zu verquicken. Es gehe schließlich um die Gelder einzelner Menschen, die ihrer dringend bedürften und die im übrigen mit ausdrücklicher Genehmigung der sowjetischen Regierung aus der Sowjetunion ausgereist seien. Im übrigen habe der Passus im Konsularvertrag über das Recht der Verwahrung nur Sinn, wenn die Betreffenden auch über ihr Geld verfügen könnten. Wenn die Bundesregierung auch nicht behaupten wolle, daß ihr aus dem Konsularvertrag ein unmittelbarer Rechtsanspruch auf Freigabe dieser Gelder erwachse, sehe sie die bisherige Regelung als völlig ungenügend an, da sie dem Geist des Vertrages widerspreche. Er bitte deshalb den Botschafter, dies seiner Regierung noch einmal vorzutragen.

Staatssekretär Carstens ging sodann zum nächsten Punkt über und sagte, er habe vor längerer Zeit sowohl mit Botschafter Smirnow als auch mit dessen Stellvertreter Timoschtschenko über den Fall des in Spandau inhaftierten Herrn Speer gesprochen ${ }^{12}$, ohne bisher eine Antwort erhalten zu haben. Er möchte hier diesen Punkt in Erinnerung bringen. Der Standpunkt der Bundesregierung dazu sei unverändert. ${ }^{13}$

Botschafter Smirnow erklärte, Speer sei durch einen internationalen Gerichtshof zu 20 Jahren Gefängnis verurteilt worden. Der Gerichtshof habe keinen Anlaß gesehen, die Frage einer Verkürzung der Strafzeit aufzuwerfen. Ebensowenig sehe die sowjetische Regierung einen Anlaß, darauf hinzuwirken, daß Herr Speer seine alte Tätigkeit unter neuen Bedingungen wieder aufnehme.

Staatssekretär Carstens erwiderte, der Gerichtshof, der das Urteil gefällt habe, sei längst aufgelöst. Seine Kompetenzen seien an die Vier Regierungen übergegangen. Ein Gnadenerlaß müsse also auch durch die Vier Regierungen erfolgen. In der ganzen Welt sei es üblich, bei so langen Haftzeiten einen Teil der Strafe zu erlassen, wenn der Häftling sich gut führe. Soviel er, der Staatssekretär, wisse, verhielten sich die drei anderen Regierungen in dieser Frage wohlwollend, so daß also die Entscheidung bei der Sowjetunion liege. Im übrigen glaube er versichern zu können, daß keine Rede davon sei, daß Herr Speer seine politische Tätigkeit jemals wieder aufnehme.

Botschafter Smirnow sagte, der ehemalige Gerichtshof sei in der Tat aufgelöst, aber das alliierte Gefängnis in Spandau bestehe noch. Daß einer als Insasse eines Gefängnisses keine neuen Verbrechen begehe, hänge mit dem Charakter einer solchen Anstalt zusammen. Der Staatssekretär versichere, Speer werde seine alte Tätigkeit nicht wieder aufnehmen. Das sei zwar gut und schön, doch stehe der Sowjetunion der Fall Foertsch als Gegenbeispiel vor Augen. Foertsch sei in der Sowjetunion zu 25 Jahren verurteilt worden, habe aber nach seiner Entlassung seine alte Tätigkeit sofort wieder aufgenommen.

12 Vgl. dazu die Aufzeichnung des Ministerialdirektors Krapf vom 14. Januar 1963; Abteilung V (V 4), VS-Bd. 294; B 150, Aktenkopien 1963.

13 Staatssekretär Carstens erklärte am 17. Januar 1961 dem sowjetischen Gesandten Timoschtschenko, „daß die Bundesregierung eine sowjetische Zustimmung zu einem Begnadigungsgesuch im Falle Speers begrüßen würde". Vgl. die Aufzeichnung des Ministerialdirektors Krapf vom 14. Januar 1963; Abteilung V (V 4), VS-Bd. 294; B 150, Aktenkopien 1963. 


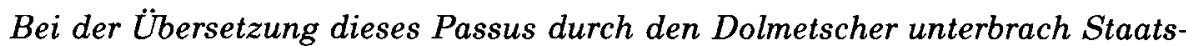
sekretär Carstens den Botschafter mit der weiter unten folgenden energischen Verwahrung.

Der Staatssekretär sage weiter, die drei Westmächte ständen einer Freilassung Speers wohlwollend gegenüber. Indessen sei ihm, dem Botschafter, nichts darüber bekannt, daß sich die Herren Kennedy, Macmillan und de Gaulle dieserhalb an Ministerpräsident Chruschtschow gewandt hätten. Im übrigen sei das Urteil gegen Speer seinerzeit von den Vier Regierungen ausdrücklich gebilligt worden.

Staatssekretär Carstens erklärte, er müsse die Unterstellung, daß General Foertsch sich in irgendeiner Weise nicht korrekt verhalte, aufs schärfste zurückweisen. Foertsch tue nichts anderes, als was Hunderte und Tausende von Generalen und Offizieren in der Sowjetunion und anderen Ländern täten. Zu der Kritik des Botschafters sei daher nicht der geringste Anlaß gegeben.

Botschafter Smirnow erwiderte, als die Bundesregierung seinerzeit um die Freilassung von Foertsch nachgesucht habe, sei mit keinem Wort davon gesprochen worden, Foertsch solle Generalinspektor der Bundeswehr werden. Wenn der Herr Staatssekretär erkläre, Foertsch tue nichts anderes als andere Generale in anderen Länder, so müsse er widersprechen. Erst kürzlich sei im Zusammenhang mit dem deutsch-französischen Abkommen ${ }^{14}$ erneut das Ziel proklamiert worden, „Europa“ unter Beseitigung der sozialistischen Regime in Osteuropa bis zum Ural auszudehnen. ${ }^{15}$ Das heißt, man verfolge genau das gleiche Ziel wie früher, und derjenige, dem die Durchführung dieser Aufgabe anvertraut worden sei, sei ausgerechnet der als Kriegsverbrecher verurteilte Herr Foertsch, der also doch die gleiche Tätigkeit wieder aufgenommen habe, die er seinerzeit vor Leningrad ausgeübt habe. Man müsse deshalb mit Recht befürchten, daß Heer Speer, kaum entlassen, in der Bundesrepublik Raketenabschußbasen, die dem gleichen Ziele dienten, Europa bis zum Ural auszudehnen, bauen werde. Er glaube deshalb, daß die sowjetische Regierung in der Frage der Freilassung Speers selbst dann zögern würde, wenn sich die drei Westmächte mit einem entsprechenden Vorschlag an sie wendeten.

Staatssekretär Carstens wies die Angriffe gegen General Foertsch erneut scharf zurück und sagte, kein Mensch in Deutschland, der seine fünf Sinne beisammen habe, habe die Absicht, die Sowjetunion anzugreifen. Er sei überzeugt, daß Botschafter Smirnow aufgrund seiner zahlreichen Kontakte mit den Menschen in der Bundesrepublik dies aus eigener Beobachtung am be. sten wisse.

Botschafter Smirnow meinte, die Sowjetische Botschaft habe auch im Dritten Reich Kontakte gehabt. Das habe nicht verhindert, daß das Unsinnige geschehen sei.

Staatssekretär Carstens sagte dagegen, die Bundesrepublik werde heute anders regiert als damals; darin liege die Garantie, daß sich derartiges nicht wiederholen werde.

14 Zum deutsch-französischen Vertrag vom 22. Januar 1963 vgl. Dok. 44, Anm. 3.

$15 \mathrm{Zu}$ der entsprechenden Äußerung des Staatspräsidenten de Gaulle vgl. Dok. 57, Anm. 8. 
Staatssekretär Carstens ging sodann zum nächsten Punkt über und erklärte, die Bundesregierung habe seinerzeit den wegen Spionage verhafteten und verurteilten sowjetischen Staatsangehörigen Pripolzew, Mitglied der sowjetischen Handelsvertretung in Köln, entlassen. ${ }^{16}$ In diesem Zusammenhang seien verschiedene Gespräche geführt worden, u. a. auch zwischen ihm, dem Staatssekretär, und dem Botschafter. Dabei habe er, der Staatssekretär, den Wunsch der Bundesregierung nach Freilassung der beiden in der Sowjetunion inhaftierten deutschen Studenten Sonntag und Naumann als Gegenleistung für die Entlassung Pripolzews vorgebracht. ${ }^{17}$ Der Botschafter habe damals erklärt, die Bundesregierung solle dies nicht zur Bedingung machen. Vielmehr wolle man ein Gentleman Agreement schließen. Es genüge, wenn der Staatssekretär ihm, dem Botschafter, gegenüber zum Ausdruck bringe, daß die Bundesregierung mit der Entlassung der beiden Studenten rechne. Ihm, dem Staatssekretär, liege diese Angelegenheit auch deshalb besonders am Herzen, weil er sich persönlich engagiert habe und in der Bundesregierung, wo die Meinungen geteilt gewesen seien, für den Vorschlag des Botschafters eingetreten sei, mit der Begründung, es sei dies ein Fall, wo die Bundesrepublik ihren guten Willen zur Verbesserung der Beziehungen mit der Sowjetunion unter Beweis stellen könne, und unter ausdrücklichem Hinweis auf die ihm von Botschafter Smirnow abgegebene Versicherung.

Seitdem sei ein Jahr vergangen, ohne daß die beiden Studenten repatriiert worden wären. Wenn er sich auch darüber klar sei, daß eine Abrede, wie sie zwischen ihm und dem Botschafter getroffen worden sei, keinen unmittelbaren Anspruch begründe, möchte er doch bitten, daß der Botschafter alles tue, damit der bei ihm, dem Staatssekretär, seinerzeit hervorgerufene Eindruck nicht Lügen gestraft werde.

Botschafter Smirnow (in sichtlicher Verlegenheit) sagte, er erinnere sich sehr wohl an dieses Gespräch. Er habe seinerzeit gesagt, man könne Pripolzew nicht mit den in der Sowjetunion der Spionage überführten deutschen Staatsangehörigen auf eine Stufe stellen. Erstens sei Pripolzew unschuldig gewesen, und zweitens sei er unter Verletzung seiner ihm als Mitglied der Handelsvertretung, die ein Teil der Sowjetischen Botschaft sei, vertraglich zugesicherten Immunität verhaftet worden. Er, der Botschafter, habe dann weiter ausgeführt, daß die Freilassung Pripolzews die Lage der in der Sowjetunion inhaftierten Personen keinesfalls verschlechtern würde. Diese Voraussage habe sich auch erfüllt. Zwei Personen seien kurz nach dem Eintreffen Pripolzews in der Sowjetunion in die Bundesrepublik entlassen worden. Auch im Hinblick auf die beiden übrigen Personen sei eine Verschlechterung ihrer Lage, etwa durch Verschärfung ihres Regimes oder dergleichen, keineswegs eingetreten. Andererseits hätte das Gericht aber auch keinen Anlaß gesehen, die Betreffenden vorzeitig zu entlassen. Nichtsdestoweniger werde er bei seiner Regie-

16 Valentin Pripolzew wurde am 25. August 1961 verhaftet und am 10. Februar 1962 wegen Militärspionage zu vier Jahren Haft verurteilt. Vgl. dazu AdG 1962, S. 9673.

17 Die Frage war auch Gegenstand des Gesprächs zwischen Bundeskanzler Adenauer und Botschafter Smirnow am 6. Juni 1962. Vgl. Büro Staatssekretär, VS-Bd. 446; B 150, Aktenkopien 1962. Zur Frage der Entlassung von Walter Naumann und Peter Sonntag aus sowjetischer Haft vgl. weiter Dok. 384 . 
rung anfragen und um Information über den derzeitigen Stand der Angelegenheit bitten.

Staatssekretär Carstens sagte, er würde dies sehr begrüßen, möchte aber der Ordnung halber bemerken, daß Pripolzew keineswegs unschuldig gewesen sei - nicht umsonst habe er bei seiner Verhaftung ein inkriminierendes Papier zu verschlucken versucht -, er habe aber auch nicht die Immunität besessen, da diese laut besonderer Abmachung über den Status der sowjetischen Handelsvertretung nur deren Leiter und seinen zwei Stellvertretern zuerkannt worden sei $^{18}$, zu welchem Personenkreis Pripolzew nicht gehört habe.

Botschafter Smirnow sagte, man wisse wohl, wie die Bundesregierung Verträge auslege. Nicht nur der Fall Pripolzew, sondern auch das Röhrenembargo hätten das zur Genüge erwiesen.

Staatssekretär Carstens reservierte sich seine Antwort auf die Frage des Röhrenembargos und sagte in Fortsetzung seiner Argumentation im Fall Pripolzew, es sei auch nicht richtig, daß das Gentleman Agreement beinhaltet habe, daß sich die Lage der in der Sowjetunion Inhaftierten nicht verschlechtern werde. Vielmehr sei mit aller Deutlichkeit ausgesprochen worden, welche Erwartung die Bundesregierung an die Freilassung Pripolzews knüpfe, und in dieser Erwartung habe ihn der Botschafter bestärkt.

Was schließlich das Röhrenembargo angehe, so behaupte die sowjetische Regierung auch in ihrer letzten Note an die Bundesregierung aus Anlaß des deutsch-französischen Vertrages ${ }^{19}$ wieder, es stelle eine Verletzung des deutsch-sowjetischen Handelsabkommens dar. Dem müsse energisch widersprochen werden. Da es sich bei den Röhren-Kontrakten um Lohnveredelungsgeschäfte ${ }^{20}$ handele, die als solche nicht Gegenstand des Abkommens seien, könne dieses auch nicht verletzt worden sein, als die Bundesregierung diese Geschäfte unterbunden habe. Im übrigen seien in früheren Jahren derartige Geschäfte, obwohl nicht im Vertrag vorgesehen, mehrfach genehmigt worden.

Botschafter Smirnow entgegnete, in der Tat seien sechs Jahre lang aufgrund des Abkommens derartige Röhren geliefert worden. Nun aber sei die Lieferung untersagt worden, obwohl die Rohre nach wie vor im Vertrag stünden. Im übrigen sei die Frage des Lohnveredelungsgeschäfts ohne Belang, da die Bundesregierung ja gar nicht wirtschaftliche Gründe für die Verhängung des Embargos geltend gemacht habe, sondern ausdrücklich militärpolitische. Bundesaußenminister Schröder habe im Bundestag wörtlich erklärt, man habe die sowjetische Strategie mit dem Embargo an ihrer empfindlichsten Stelle getroffen, und die Reaktion der sowjetischen Regierung zeige, daß man mit dieser Maßnahme auf dem richtigen Wege sei.

Staatssekretär Carstens bestritt, daß der Minister eine solche Bemerkung getan habe. Zunächst aber gehe es um die Behauptung der Vertragsverletzung.

18 In der Anlage zum Handels- und Seeschiffahrtsabkommen vom 25. April 1958 wurde in Artikel 2c sowohl dem Leiter der sowjetischen Handelsvertretung als auch den Stellvertretern diplomati. sche Immunität eingeräumt. Vgl. BundesgesetzBlatT 1959, Teil II, S. 225.

19 Zur sowjetischen Note vom 17. Mai 1963 vgl. Dok. 176.

20 Vgl. dazu Dok. 11, Anm. 8. 
Die Frage Lohnveredelungsgeschäft oder Liefergeschäft sei kein bloßer Unterschied im Verrechnungsverfahren, wie die sowjetische Seite behaupte, vielmehr werde im internationalen Handelsverkehr zwischen diesen beiden Geschäften scharf unterschieden. Da Lohnveredelungsgeschäfte nicht Gegenstand des deutsch-sowjetischen Abkommens seien ${ }^{21}$, könne ihr Verbot unter gar keinen Umständen als Vertragsverletzung ausgelegt werden. Im äußersten Falle könne die sowjetische Regierung geltend machen, daß sich die Bundesregierung in diesem Falle nicht freundlich verhalten habe. Die Bundesregierung habe diese Frage jedoch nicht allein entschieden, sie sei vielmehr an ihre atlantischen Partner gebunden, und diese seien einhellig der Ansicht, daß das weit nach Westen vorgetriebene sowjetische Röhrennetz ${ }^{22}$ für den Fall eines sowjetischen Aufmarsches von größter strategischer Bedeutung sei. ${ }^{23}$

Botschafter Smirnow verwies darauf, daß Rohrleitungen von Toulon nach Mannheim und von der Nordsee her ins Ruhrgebiet liefen, denen man sicherlich auch strategische Bedeutung unterschieben könne. Im übrigen seien die in der Bundesrepublik bestellten Rohre für eine Gasleitung nach Sibirien bestimmt gewesen. Aber wie dem auch sei, ob er den Herrn Staatssekretär so verstehen dürfe, daß die Bundesrepublik bereit sei, Röhren in beliebiger Menge an die Sowjetunion zu liefern, sofern dies nicht im Rahmen von Lohnveredelungsgeschäften geschehe? In diesem Falle würde er die sowjetischen Außenhandelsorganisationen in diesem Sinne informieren.

Staatssekretär Carstens erwiderte, er habe sich darauf beschränkt, nachzuweisen, daß die Untersagung der vorgesehen gewesenen Geschäfte keinen Vertragsbruch darstelle. Darüberhinaus bleibe die Angelegenheit ein schwieriges Problem, wobei die Bundesrepublik nicht allein stehe.

Botschafter Smirnow sagte, die Engländer seien im Gegensatz zur Bundesregierung bereit, Röhren zu liefern. ${ }^{24}$ Die englische Regierung sei jedoch von Bundesaußenminister Schröder darauf aufmerksam gemacht worden, wenn England liefere, könne sich dies nur nachteilig auf die deutsch-britischen Beziehungen auswirken. ${ }^{25}$ Dies sei eine klare Drohung, die einen weiteren unfreundlichen Akt gegen die Sowjetunion einschließe. Statt dessen hätte sich die Bundesregierung lieber dem englischen Beispiel anschließen sollen.

Staatssekretär Carstens entgegnete, es handele sich hierbei um eine Frage der atlantischen Partnerschaft. Da ein gemeinsamer Beschluß aller NATO-Mitgliedstaaten gefaßt worden sei, den die Bundesregierung gegen erhebliche innere Kritik durchgeführt habe ${ }^{26}$, gehe es nicht an, daß ein anderer Partner die Lieferung vornehme, die die Bundesregierung deutschen Firmen untersagt habe, ohne daß die Bundesregierung innenpolitisch in eine höchst schwierige Lage gerate. Im übrigen handele es sich offenbar nicht um eine andere Auffassung der englischen Regierung, sondern um Unterschiede in der deutschen

21 Zum Warenabkommen mit der UdSSR vom 31. Dezember 1960 vgl. Dok. 23, Anm. 5.

22 Die „Freundschaftslinie“" sollte bis in das Gebiet der DDR führen. Vgl. dazu Dok. 11, Anm. 12.

$23 \mathrm{Vgl}$. dazu bereits Dok. 148.

24 Vgl. dazu den Vermerk des Staatssekretärs Lahr vom 18. Mai 1963; Büro Staatssekretär, Bd. 407.

25 Vgl. dazu Dok. 131 und Dok. 144.

26 Vgl. dazu Dok. 123, Anm. 5 und 6. 
und der englischen Gesetzgebung. Auf keinen Fall sei diese Äußerung des Ministers als unmittelbar gegen die Sowjetunion gerichtet zu verstehen.

Das Gespräch war um 12.30 Uhr beendet.

Büro Staatssekretär, Bd. 400.

\section{Gespräch des Bundesministers Schröder mit dem kanadischen Außenminister Martin in Ottawa}

MB 1480/63 VS-vertraulich

20. Mai $1963^{1}$

Der Bundesminister des Auswärtigen Dr. Gerhard Schröder führte am 20. Mai 1963, 10.30 Uhr, in Ottawa ein Gespräch mit dem kanadischen Außenminister Martin. Bei der Unterredung waren außerdem Botschafter Siegfried, der kanadische NATO-Botschafter ${ }^{2}$ und Mr. Richardson zugegen.

Hinsichtlich der Frage der nuklearen Sprengköpfe für die kanadischen Streitkräfte $^{3}$ fragte der Herr Minister, ob die Auffassung der Partei des Außenministers Martin nicht im Wahlkampf praktisch schon gesiegt habe.

Außenminister Martin wies darauf hin, daß seine Partei zwar die meisten Sitze errungen habe, aber im Parlament nicht die absolute Mehrheit habe. ${ }^{4}$ Die kanadische Regierung stelle sich auf den Standpunkt, daß das kanadische Volk sie bevollmächtigt habe, mit den Amerikanern ein Abkommen über die Lagerung nuklearer Sprengköpfe unter amerikanischer Kontrolle und Verwahrung zu schließen. ${ }^{5}$ Die Opposition ${ }^{6}$ werde wahrscheinlich argumentieren, daß die Regierung nicht berechtigt sei, ein Abkommen mit den Amerikanern zu schließen, ehe das Parlament in der Frage der nuklearen Waffen einen formellen Beschluß gefaßt habe. Vertraulich wolle er dem Herrn Minister sagen,

1 Die Gesprächsaufzeichnung wurde vom Vortragenden Legationsrat Kusterer am 20. Mai 1963 gefertigt.

Hat Bundesminister Schröder am 13. Juni 1963 vorgelegen, der handschriftlich vermerkte: „1) Original zur Sammlung. 2) Im übrigen übliche Verteilung.“

2 George Ignatieff.

3 Zwischen den USA und Kanada war es Anfang $1963 \mathrm{zu}$ diplomatischen Spannungen gekommen, da sich die kanadische Regierung dem amerikanischen Drängen, einer Ausstattung kanadischer Streitkräfte mit Atomwaffen zuzustimmen, widersetzte. Ein Mißtrauensvotum des kanadischen Parlaments am 5. Februar 1963 führte zum Sturz der konservativen Regierung unter Ministerpräsident Diefenbaker. Vgl. AdG 1963, S. 10416.

4 Am 8. April 1963 fanden in Kanada Parlamentswahlen statt, bei denen die Liberale Partei eine relative Mehrheit der Parlamentssitze erringen konnte. Neuer Ministerpräsident wurde Lester B. Pearson. Vgl. AdG 1963, S. $10534 \mathrm{f}$.

5 Ministerpräsident Pearson gab am 16. August 1963 bekannt, daß Kanada und die USA eine Vereinbarung über die Ausrüstung der kanadischen Luftwaffe mit amerikanischen Nuklearspreng köpfen unter gemeinsamer Kontrolle getroffen hätten. Vgl. AdG 1963, S. 10753.

6 Die Opposition im kanadischen Parlament stellten nach dem 8. April 1963 die Konservative Partei, die Sozialkreditpartei und die Neue Demokratische Partei. 
daß die kanadische Regierung das Abkommen mit Amerika nicht endgültig schließen werde, ehe sich das Parlament in der einen oder anderen Form dazu geäußert habe. Auch die kanadischen Streitkräfte in Europa seien noch nicht mit nuklearen Sprengköpfen ausgerüstet. Seine Regierung vertrete den Standpunkt, daß es eine Verpflichtung Kanadas gegenüber Amerika gebe, die es honorieren müsse. Dies schließe aber eine Überprüfung und neue Aushandlung irgendwelcher Aktionen nicht aus. Hier passe der Vorschlag des Generalsekretärs der $\mathrm{NATO}^{7}$ sehr gut in die kanadische Auffassung. Die sozialistischen Parteien würden sich sicherlich gegen diese Auffassung aussprechen, während die Konservativen in dieser Frage geteilter Meinung seien. Er hoffe, daß es gelingen werde, die Kanadier davon zu überzeugen, daß ein Abkommen über die Lagerung amerikanischer Sprengköpfe unter amerikanischem Verschluß keine Ausweitung des nuklearen Clubs bedeute. Bei den Sprengköpfen handle es sich um die atomare Munition für die in Deutschland stationierten F-104 und die Honest John-Raketen sowie für die auf kanadischem Gebiet stationierten Voodoo und Bomarc.

Der Herr Minister wies darauf hin, daß das vorgesehene Abkommen ja keine Verbreitung nationaler nuklearer Waffen, sondern ein integriertes System darstelle. ${ }^{8}$ In der Interalliierten Streitmacht sei der britische Bestandteil die einzige Ausnahme, da er über eigene nukleare Kräfte verfüge. Die Bundesregierung halte ebenfalls die Verbreitung nationaler nuklearer Kräfte für unerwünscht und unterstütze gerade deswegen eine hochintegrierte Streitmacht.

Außenminister Martin bemerkte, die Schaffung einer kollektiven Kontrolle bei der IANF oder MLF ${ }^{9}$ ändere an dem wirklichen Verhältnis nicht sehr viel, weil die Amerikaner immer noch die Kontrolle über die nuklearen Köpfe hätten.

Der Herr Minister legte dar, je mehr die übrigen Partner an der Kontrolle und Planung beteiligt seien, desto günstiger sei die psychologisch-politische Situation für die Allianz. Es sei nämlich ein großer Unterschied, ob die Amerikaner die gesamte Planung und Organisation ganz allein betrieben, oder ob die anderen Partner daran möglichst stark beteiligt seien, selbst wenn die letzte Entscheidung bei den Amerikanern verbliebe. Dies müsse betont werden, weil es in Europa sehr leicht eine nicht nur von französischer Seite ausgehende Propaganda gebe, daß all dieses nur bedeute, daß man für Waffen zahle, über die Amerika verfüge. ${ }^{10}$ Dadurch würde aber der politische Effekt zerstört.

7 Auf der Tagung des NATO-Ministerrats vom 22. bis 24. Mai 1963 in Ottawa brachte Generalsekretär Stikker den Vorschlag vor, Teile bereits bestehender nationaler nuklearer Streitkräfte zu einer Inter-Allied Nuclear Force als Vorstufe einer multilateralen Atomstreitmacht der NATO zusammenzufassen. Vgl. dazu bereits Dok. 158; weiter Dok. 190.

8 Die UdSSR hatte gegen die Weitergabe amerikanischer atomarer Sprengköpfe innerhalb der NATO protestiert. Zum Notenwechsel vom April/Mai 1963 vgl. Dok. 116, Anm. 19.

9 Zur administrativen Kontrolle einer multilateralen Atomstreitmacht durch ein „executive committee" vgl. Dok. 120, besonders Anm. 12. Vgl. dazu auch das Schreiben des Bundeskanzlers Adenauer vom 4. April 1963 an Präsident Kennedy; Ministerbüro, VS-Bd. 8475; B 150, Aktenkopien 1963.

10 In diesem Sinne äußerte sich beispielsweise Staatspräsident de Gaulle am 22. Januar 1963 gegenüber Bundeskanzler Adenauer. Vgl. Dok. 43. Vgl. dazu auch die Ansichten des französischen Informationsministers Peyrefitte; Dok. 168. 
Außenminister Martin bezeichnete die multilaterale Streitmacht als den Idealzustand und die Interalliierte Streitmacht als eine Brücke dorthin. Allerdings tue Kanada im Augenblick nicht sehr viel zur Ermutigung der multilateralen Streitmacht. ${ }^{11}$

Herr Minister räumte ein, daß die MLF noch längerer Erörterungen bedürfe. Er wies in diesem Zusammenhang darauf hin, daß die Bundesrepublik keine europäische nukleare Streitmacht befürworte, sondern eine integrierte Streitmacht der Allianz unterstütze, denn die enge Verbindung durch amerikanische und kanadische Streitkräfte in Europa und durch eine integrierte Nuklearmacht sei für sie entscheidend.

Außenminister Martin sagte, nach seiner Kenntnis gebe es in Deutschland heute eine starke Bewegung für eine deutsche national-nukleare Ausrüstung.

Der Herr Minister bestritt dies, wies aber darauf hin, daß man einer solchen Entwicklung, die zwangsläufig einsetzen würde, falls sich die nationalen $\mathrm{Nu}$ klearkräfte vervielfältigten, vorbeugen müsse. Gerade deswegen sei die richtige Antwort: eine integrierte Streitmacht der ganzen Allianz.

Außenminister Martin sagte, dies sei wohl der Grund, warum der Vorschlag der MLF gemacht worden sei.

Der Herr Minister bemerkte, es sei einer der Gründe, doch sei dieser Gedanke nicht nur aus der deutschen Perspektive wichtig. Die nukleare Frage könne tatsächlich die NATO beeinträchtigen, wenn nicht ein gemeinsames Regime etwa in der Form der MLF gefunden würde. Entscheidend sei der Zusammenhalt der Allianz, und einer Desintegration könne am ehesten durch Integration begegnet werden.

Außenminister Martin betonte dann, das Bündnis müsse auch das Problem der Stärkung der konventionellen Streitkräfte bewältigen. ${ }^{12}$ Ohne dafür präzise Anhaltspunkte zu haben, glaube er, daß die Vereinigten Staaten ihre konventionellen Kräfte auf dem Kontinent verstärken werden. Er werde $\mathrm{McNa}$ mara ganz einfach fragen.

Der Herr Minister äußerte gewisse Zweifel hierüber und bemerkte, die Amerikaner dächten nach seinen Informationen eher daran, daß die anderen die konventionellen Kräfte erhöhten. Die konventionelle Rüstung der Bundesrepublik wachse, doch gebe es hier natürlich gewisse Grenzen. Erforderlich sei s. E. eine glaubwürdige Abschreckung, die sich aus einem ausgeglichenen konventionellen und nuklearen Teil zusammensetze.

Abschließend lud der Herr Minister Außenminister Martin ein, bei seiner nächsten Europareise doch einen Besuch in Bonn und Berlin mit einzuplanen. ${ }^{13}$

Ministerbüro, VS-Bd. 8510

11 Diese Haltung drückte sich auch in der Erklärung des Ministerpräsidenten Pearson am 7. Juni 1963 vor dem kanadischen Unterhaus aus, Kanada werde sich an der multilateralen Atomstreit macht nicht beteiligen. Vgl. dazu den Bericht des Gesandten Hartlieb, Ottawa, vom 14. Juni 1963; Abteilung II (II 7), VS-Bd. 1347; B 150, Aktenkopien 1963.

12 Zur Strategie der „flexible response“ vgl. Dok. 83, Anm. 7.

13 Der kanadische Außenminister Martin besuchte am 15./16. Mai 1964 die Bundesrepublik. 


\section{Staatssekretär Carstens an Bundesminister Schröder, z.Z. Ottawa}

St.S. 881/63 VS-vertraulich

Aufgabe: 20. Mai 1963, 11.00 Uhr

Fernschreiben Nr. 61

Citissime mit Vorrang

Für den Herrn Minister

I. Die sowjetische Note vom 17. Mai ${ }^{1}$ zum deutsch-französischen Vertrag ${ }^{2}$ ist nach meiner Ansicht eine der schwächsten Leistungen der Sowjets in unserem jahrelangen Notenaustausch mit ihnen. Dazu einige Beispiele:

1) Der deutsch-französische Vertrag wird als militaristische Allianz innerhalb der NATO bezeichnet, fast der gesamte Inhalt des Vertrages laufe auf gemeinsame militärische Vorbereitungen hinaus.

2) Uns wird unterstellt, daß wir Kernwaffen haben wollten, weil wir ihren Besitz als Attribut der Souveränität ansähen. ${ }^{3}$

3) Die Tatsache, daß die SBZ bereits eine stattliche bewaffnete Streitkraft aufgestellt hatte, bevor in der Bundesrepublik der erste Mann einberufen wurde, wird selbstverständlich wieder unterschlagen, wenn uns der Vorwurf gemacht wird, wir hätten durch die Wiederbewaffnung internationale Abkommen ${ }^{4}$ verletzt.

4) Wieder wird die bereits oft widerlegte falsche Behauptung aufgestellt, wir hätten das deutsch-sowjetische Handelsabkommen ${ }^{5}$ (gemeint ist wohl durch das Röhrenembargo ${ }^{6}$ ) verletzt. ${ }^{7}$

5) Völlig abwegig sind - angesichts der flagranten Verletzungen des Berlinstatus in Ostberlin - die Vorwürfe, wir verletzten den Status Westberlins.

6) Auf unseren Vorschlag, die Meinung der Bevölkerung der SBZ zum deutsch-französischen Vertrag zu erfragen ${ }^{8}$, wird geantwortet, dies sei nicht

1 Für den Wortlaut vgl. DzD IV/9, S. 347-352.

2 Zum deutsch-französischen Vertrag vom 22. Januar 1963 vgl. Dok. 44, Anm. 3.

Für den Wortlaut der sowjetischen Protestnote vom 5. Februar 1963 gegen den Vertrag vgl. DzD IV/9, S. 86-92.

3 So auch in der sowjetischen Note vom 8. April 1963 zur integrierten Atomstreitmacht der NATO. Vgl. dazu Dok. 116, Anm. 19.

4 Das Kommuniqué vom 2. August 1945 über die Konferenz von Potsdam (Potsdamer Abkommen) sah eine vollständige Entmilitarisierung Deutschlands vor. Für den Wortlaut des Abschnitts III. A. 3. vgl. DzD II/1, S. $2106 \mathrm{f}$.

5 Zum Warenabkommen mit der UdSSR vom 31. Dezember 1960 vgl. Dok. 23, Anm. 5.

6 Zur Verordnung vom 18. Dezember 1962 über die Ausfuhr von Röhren vgl. Dok. 9, Anm. 6.

$7 \mathrm{Zu}$ dieser Argumentation vgl. bereits Dok. 174.

Zur sowjetischen Protestnote vom 6. April 1963 vgl. Dok. 148, Anm. 4.

8 In der Note an die UdSSR vom 29. März 1963 brachte die Bundesregierung zum Ausdruck, daß sie durchaus bereit gewesen wäre, ,auch die Deutschen in der sogenannten DDR zu fragen, ob sie diese Aussöhnung wollten, und sie ist sich völlig sicher, daß auch die überwältigende Mehrheit 
mehr nötig, denn die Regierung der SBZ habe diese Meinung zum Ausdruck gebracht.

7) Auch was über unsere angebliche Politik der verpaßten Gelegenheiten in der Wiedervereinigungsfrage gesagt wird, erscheint mir denkbar schwach.

II. Genauere Analyse ${ }^{9}$ folgt. Antwort wird beschleunigt entworfen. ${ }^{10}$ Mit Franzosen wird Fühlung genommen.11

Carstens $^{12}$

Büro Staatssekretär, VS-Bd. 442

\section{7}

\section{Gespräch des Bundesministers Schröder mit dem französischen Außenminister Couve de Murville in Ottawa}

MB 1478/63 VS-vertraulich

21. Mai $1963^{1}$

Der Bundesminister des Auswärtigen Dr. Gerhard Schröder führte am 21. Mai 1963, $11.00 \mathrm{Uhr}$, in Ottawa ein Gespräch mit dem französischen Außenminister Couve de Murville.

Zur bevorstehenden NATO-Konferenz bemerkte Couve de Murville, Frankreich könne mit der Formulierung des Kommuniqué-Entwurfs zur nuklearen Streitmacht ${ }^{2}$ einverstanden sein. An der gegenwärtigen Organisation und den derzeitigen Aufgaben von SACEUR ändere sich ja nichts. Durch die Hinzufügung der britischen V-Bomberflotte ${ }^{3}$, die im Gegensatz zu früher nunmehr taktische Aufgaben zugewiesen bekomme, werde lediglich ein Teil der bisher vom SAC wahrgenommenen Ziele von der SACEUR unterstehenden Nuklear-

Fortsetzung Fußnote von Seite 578

der dort lebenden Deutschen dem Vertrag ihre Zustimmung gegeben hätte“. Vgl. Bulletin 1963, S. $521 \mathrm{f}$.

9 Vgl. dazu die Aufzeichnung des Legationsrats I. Klasse Wolff vom 22. Mai 1963; Abteilung II (II 4), VS-Bd. 197.

10 Für den Wortlaut der Antwortnote vom 23. August 1963 vgl. Bulletin 1963, S. 1321.

11 Die französische Antwortnote vom 23. August 1963 war mit der deutschen identisch. Vgl. dazu Europa-Archiv 1963, D 527.

$\mathrm{Zu}$ früheren deutsch-französischen Konsultationen über ein gemeinsames Vorgehen gegen die sowjetischen Proteste vgl, auch Dok. 126.

12 Paraphe vom 20. Mai 1963.

1 Die Gesprächsaufzeichnung wurde vom Vortragenden Legationsrat Kusterer am 21. Mai 1963 gefertigt.

Hat Bundesminister Schröder am 23. Mai 1963 vorgelegen, der am 13. Juni 1963 handschriftlich vermerkte: „1) Original hier behalten. 2) Im übrigen übliche Verteilung.“

2 Für den deutschen Wortlaut des Kommuniqués vom 24. Mai 1963 vgl. Bulletin 1963, S. 811.

3 Zur Bedeutung der britischen Bomberflotte vgl. auch Dok. 143, Anm. 17. 